\title{
Un aequipondium de peso excepcional y la balanza pública del puerto de Tarraco
}

\section{An exceptional weighing aequipondium and the public scales of the harbour of Tarraco}

\author{
Francesc Rodríguez Martorell ${ }^{1}$ \\ Institut Català d'Arqueologia Clàssica, Tarragona \\ Joaquín Ruiz de Arbulo Bayona ${ }^{2}$ \\ Universitat Rovira i Virgili / Institut Català d'Arqueologia Clàssica, Tarragona \\ con un anexo de Ignacio Montero ${ }^{3}$ \\ Instituto de Historia del CSIC
}

\section{RESUMEN}

Estudiamos un aequipondium o contrapeso de balanza realizado en bronce con representación figurada de una divinidad femenina. Apareció en la fachada portuaria de Tarragona y está conservado en la colección del Museu Nacional Arqueològic de Tarragona (MNAT). Destacamos su peso excepcional de $38 \mathrm{~kg}$, el mayor, con diferencia, de todos los aequipondia hasta ahora conocidos en el mundo romano. Pertenecería a una gigantesca statera o balanza de brazo, que hoy denominamos romana. Esta balanza estaría necesariamente montada en un gran bastidor o machina, capaz de pesar cargas enormes de hasta $1500 \mathrm{~kg}$ o más. Por el lugar de hallazgo y sus altas cualidades artísticas y técnicas proponemos relacionarlo con la balanza pública (ponderarium o sacomarium) del puerto de Tarraco. La divinidad femenina representada debe ser una imagen de Aequitas, la Equidad, numen protector de las justas transacciones en las pesas y medidas de los mercados.

\section{SUMMARY}

We studied an aequipondium or counterweight balance in bronze with figurative representation of a female divinity. $\mathrm{He}$ appeared in front of Tarragona port and is preserved in the collection of the National Archaeological Museum of Tarragona (MNAT). We emphasize its exceptional weight of $38 \mathrm{~kg}$, the largest, far ahead of all aequipondia hitherto known in the Roman world. Statera belong to a giant or balance arm. This scale would necessarily be mounted on a large frame or machina, capable of weighing huge loads of up to $1500 \mathrm{~kg}$ or more. By place of discovery and its high artistic and technical qualities propose relate to public balance (ponderarium or sacomarium) of roman port. The female divinity represented should be an image of Aequitas, Equity, numen protector of fair dealing in the weights and measures of the markets.

\footnotetext{
${ }^{1}$ frodriguez@icac.cat http://orcid.org/0000-0002-47005023

2 joaquin.ruizdearbulo@urv.cat http://orcid.org/0000-00019356-3790

3 ignacio.montero@cchs.csic.es http://orcid.org/0000-00030897-1031
}

PALABRAS CLAVE: Aequipondium; statera; machina; Tarraco; ponderarium; sacomarium; Aequitas.

KEY WORDS: Aequipondium; statera; machina; Tarraco; ponderarium; sacomarium; Aequitas.

El ponderal que analizamos en este trabajo fue encontrado en el núm. 16 de la calle Smith, cercana a la fachada portuaria de la ciudad de Tarragona, cuando se hizo la cimentación de una nueva casa en el año 1971 (PAT 2007, num. 513) ${ }^{4}$. La entrega de la pieza al entonces Museo Arqueológico Provincial fue efectuada por Francesc Ros Ribal, miembro de la Reial Societat Arqueològica Tarraconense el 3 de diciembre del mismo año. Desde entonces forma parte de la colección expositiva del hoy Museu Nacional Arqueològic de Tarragona con el número de inventario 36999. Se trata pues de un hallazgo descontex-

\footnotetext{
${ }^{4}$ Estamos en deuda con F. Tarrats y J.A. Remolà, director y conservador del Museu Nacional Arqueològic de Tarragona, por la ayuda que nos han proporcionado para efectuar la autopsia de la pieza. También hemos de agradecer a Joan Carbonell (Universidad Autónoma de Barcelona), Nuria Rafel (Universidad de Lleida), Carla Corti (Modena) y Norbert Franken (Berlín) por sus comentarios y sugerencias en diferentes momentos del estudio. Agradecemos igualmente al arquitecto Giovanni Tuzio, director del Museo Campano, sus referencias sobre el relieve con la gran statera conservado en Capua. También las facilidades que nos han proporcionado Ramon Rosich y Jordi Puig, director y conservador del $\mathrm{Mu}$ seu de la Vida Rural de l'Espluga de Francolí para examinar una gran romana de 1905 conservada en su institución. Los desarrollos epigráficos están extraídos de la base de datos Clauss-Slaby. Gracias por último a nuestra buena amiga Romana Erice (Ayunt. Zaragoza) por la lectura del texto, sus observaciones y aportación bibliográfica.
} 


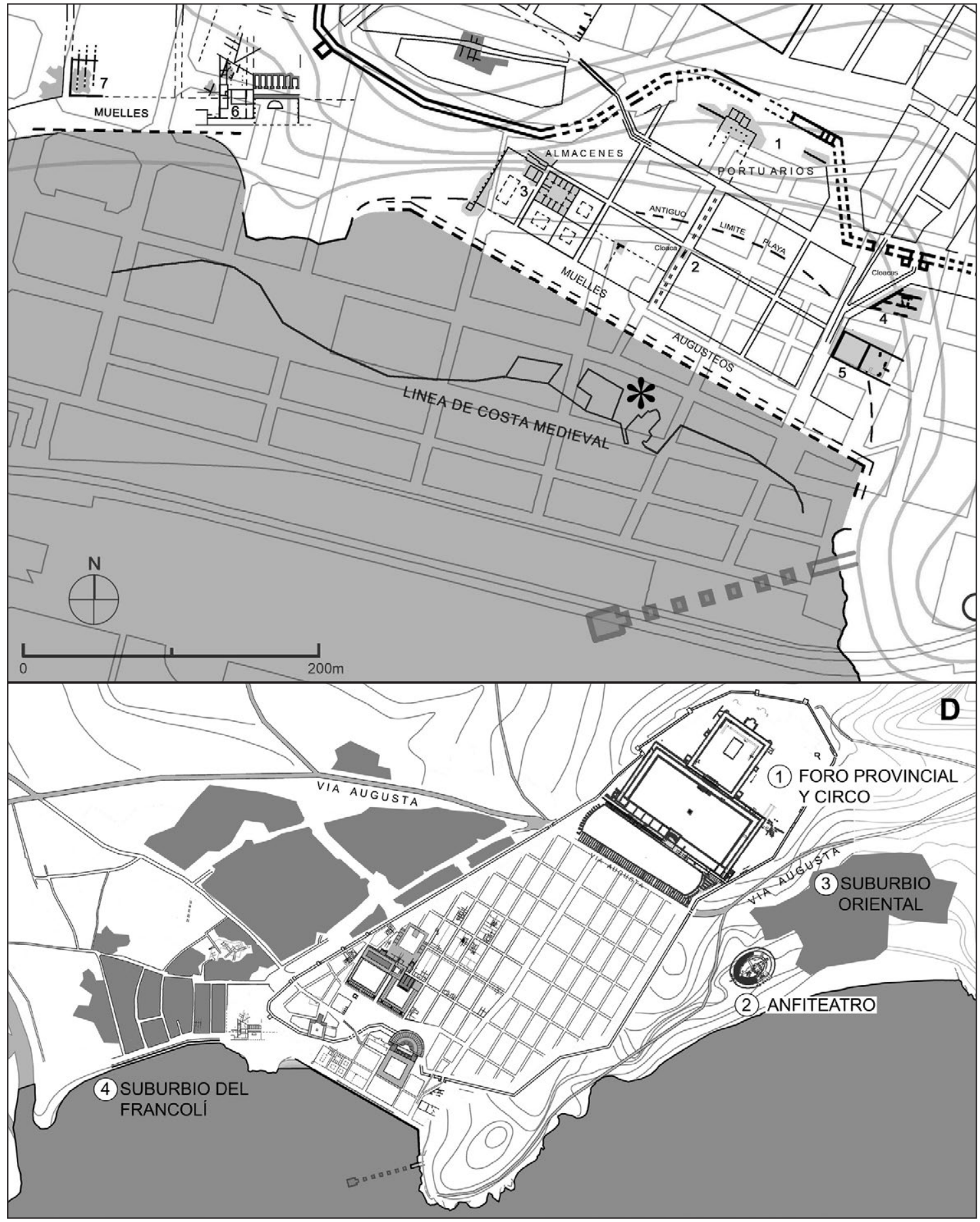

Figura 1. a. El lugar del hallazgo, en el núm 27 de la calle Smith, corresponde de forma aproximada con la posición estimada de los muelles en la ciudad romana de Tarraco. b. Restitución de la colonia Tarraco en el siglo II d.C. Planimetrías de Ricardo Mar. 


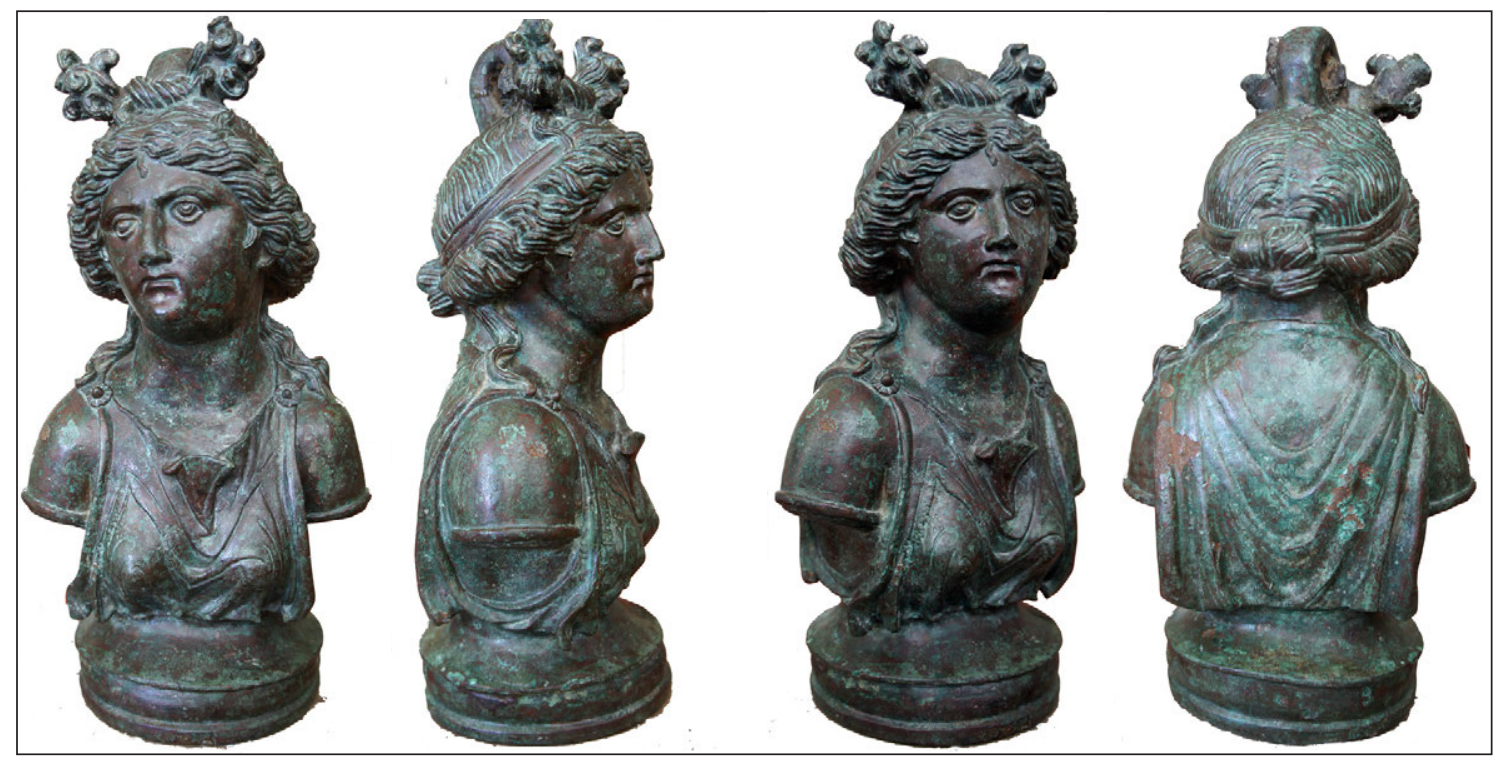

Figura 2. a, b, c, d. Aequipondium con cabeza femenina. Vistas delantera, lateral derecha, oblicua y trasera.

tualizado realizado prácticamente en el límite de la paleolínea marítima estimada para la época romana. Las noticias que pudo reunir W. Pérez (2007: 71) señalan tan solo la presencia de grandes estratos de tierras de relleno, arenas estériles y lo que se define como un fragmento de pavimentación viaria antiguo. Retenemos de cualquier forma como primer criterio de análisis la aparición en la vaguada portuaria de la ciudad.

Se trata de una pieza bien conocida, reproducida repetidas veces en catálogos de exposiciones que han resaltado ante todo la belleza de su ejecución y sus altas cualidades artísticas y técnicas. Estuvo presente, por ejemplo, en la exposición Tàrraco, objecte $i$ imatge (1987); la exposición sobre los Bronces Romanos en España (Caballero 1990: núm. 345 -I. Rodà-); la gran exposición de la Hispania Romana de 1997, (núm. 221 -F. Salcedo-); o la exposición Tarraco capitale del Musee Saint Raymond de Toulouse en el año 2006, (núm. 5.37 -P.Sada-). Hasta ahora, la investigación se había centrado esencialmente en describir las características artísticas de la imagen femenina que la decora y en su posible identificación con la diosa Diana.

Hasta la última ficha de catalogación publicada por P. Sada y D. Cazes (2006) no se ha llamado la atención de forma suficiente sobre lo que creemos debe ser el principal elemento de interés de esta pieza: un peso muy elevado de $38 \mathrm{~kg}$ que representa, como veremos a continuación, un unicum excepcional entre todos los aequipondia hasta ahora documentados, a considerable distancia del siguiente. Un ponderal móvil con este peso, de manejo fráncamente incómodo, debía corresponder a una statera o romana de dimensiones excepcionales, destinada al control de cargas enormes.

\section{CARACTERÍSTICAS TÉCNICAS}

Se trata de una bellísima pieza de gran tamaño realizada en bronce que representa el busto de una figura femenina apoyado sobre una base circular finamente moldurada. Sus dimensiones son $36 \mathrm{~cm}$ de altura por $20 \mathrm{~cm}$ de ancho y $15 \mathrm{~cm}$ de diámetro en la base. La presencia en la parte superior de la cabeza de un aro grueso sin decorar obturado todavía hoy con los restos de hierro de un gancho, permite definir sin lugar a dudas esta pieza como el contrapeso deslizante que Vitrubio $(\mathrm{X}, 4)$ denominaría aequipondium. Un peso móvil que funcionaría en una romana o balanza de brazo, una statera en términos latinos ( $D A$, s.v. libra, fig. 4481; Corti 2001a; 2001b).

La base de la pieza aparece sin acabar de trabajar y de ella aflora un elemento central de hierro rodeado por una colada de plomo. Es decir que el interior de la pieza había sido rebajado desde su parte inferior y por ella se insertó un elemento de hierro recogido y completado con plomo fundido. Tanto el vástago de hierro central como el plomo circundante sobresalen ligeramente del plano de base de forma absolutamente descuidada.

Sabemos que los aequipondia de las balanzas de brazo, normalmente realizados en bronce, solían ser rellenados con plomo para obtener así pesos prefijados 


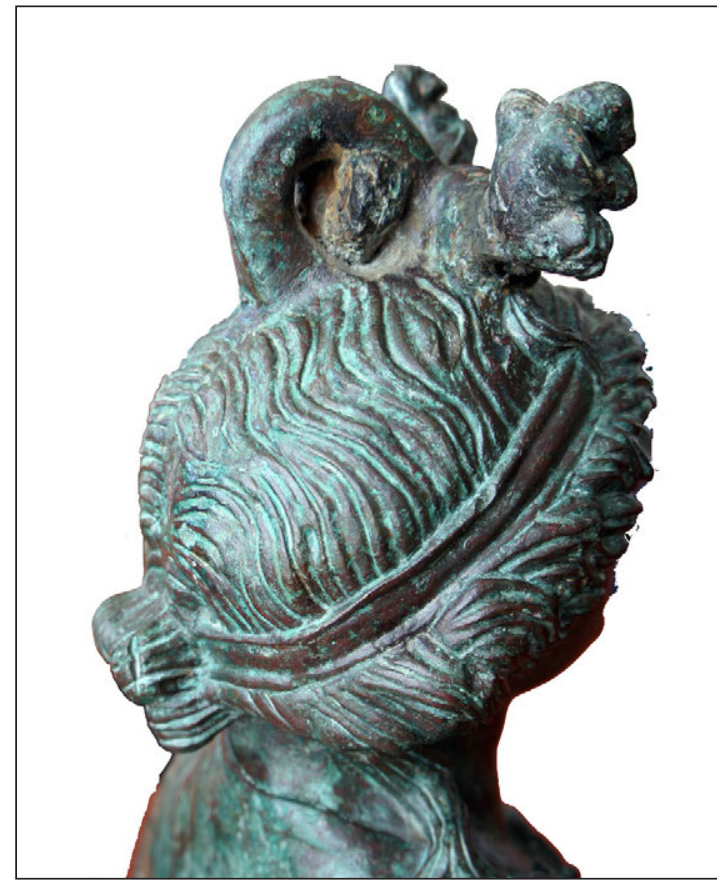

Figura 3. Detalle de la anilla maciza superior conteniendo todavía restos del gancho de hierro de suspensión del contrapeso.

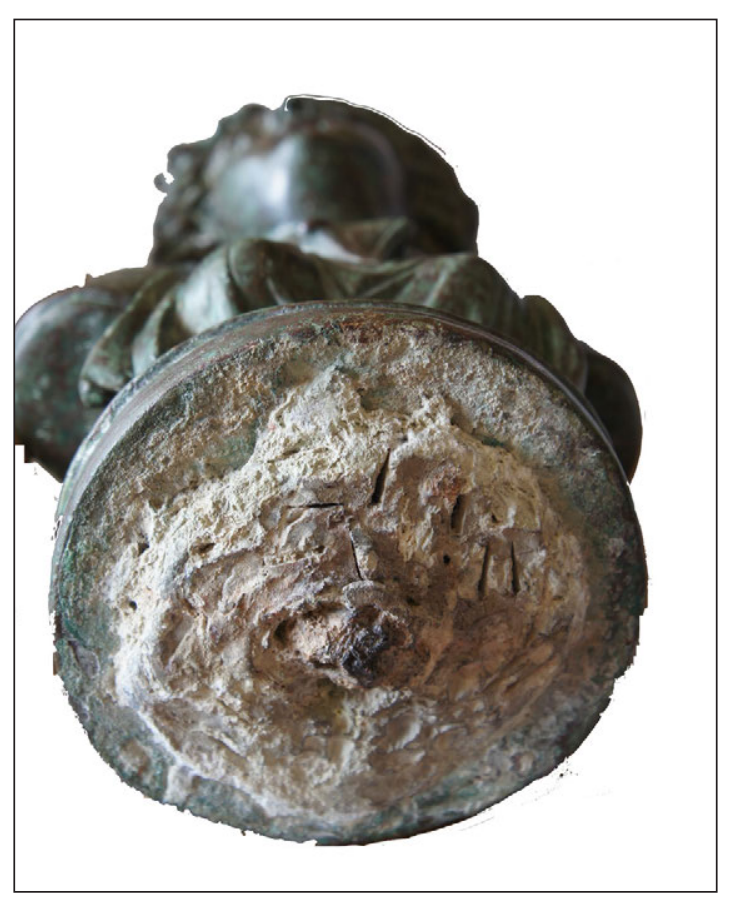

Figura 4. Vista de la base del contrapeso con elemento central de hierro ensartado tomado con plomo fundido. Las marcas de navaja fueron realizadas en el momento del hallazgo en los años 1970 para comprobar la profundidad del plomo. sobre los múltiplos y submúltiplos de la libra. En este caso, dado el gran tamaño y peso de la pieza, parece que se prefirió encajar también una pieza de hierro junto a la habitual colada de plomo. El peso del ponderal en su estado actual es de $38 \mathrm{~kg}$; unas 116 libras romanas. Si a este peso le sumamos el necesario gancho superior de anclaje al brazo de la balanza realizado en hierro — del que aun quedan restos en la anilla de coronación- y que debería sumarse al peso de nuestra pieza, creemos correcto redondear el peso total del contrapeso completo en unas 120 libras.

Sorprende la razón que pudo justificar utilizar un ponderal de un peso tan elevado en una statera o romana. La utilización de grandes y pesados ponderales de piedra era frecuente en las balanzas de dos platos por la necesidad de equilibrar la totalidad de la masa a pesar. Y ello ocurría incluso en el comercio minorista. Una pequeña nave de $12 \mathrm{~m}$ de eslora naufragada en la costa adriática de Valle Ponti (Comacchio) a fines del siglo i a. C. incluía entre su carga de lingotes de plomo un ponderal en piedra de 100 libras de peso (c. $32 \mathrm{~kg}$ ). Se trata de un ponderal muy cuidado, realizado en piedra calcárea con forma troncocónica que incluye en su parte inferior una pequeña cavidad con material extraído para controlar así un peso exacto, asa superior de hierro enmangada con plomo fundido y epígrafe $T R U F$ (ius?) M(agister?). La nave transportaba también una pequeña statera y un ánfora con indicación pintada de su tara o peso neto en caracteres griegos (Berti 1990; Corti 2001c: 319-321). Este pesado ponderal de la nave de Comacchio estuvo destinado sin duda a controlar el peso de los lingotes transportados para su venta al detalle con una gran libra o balanza de dos platos. Pero el funcionamiento de una statera era muy diferente y su contrapeso o aequipondium nunca precisaba alcanzar magnitudes tan grandes. Era mucho más simple alargar el brazo para el contrapeso.

La mayor parte de los aequipondia que vemos hoy en las vitrinas de los Museos fueron utilizados en balanzas para fines comerciales o domésticos y tenían magnitudes mucho menores, en torno a una libra romana (de 327,45 o 322,56 gr). Así ocurre por ejemplo con los 60 contrapesos de la región del Modenese revisados y medidos por R. Tarpini (2001: 311), o los inventariados por F. Chaves y R. Pliego (2007) en la Península Ibérica, con nuevos ejemplares que siguen apareciendo de forma frecuente (ver por ejemplo Erice 2015).

En el completo y muy útil catálogo de Norbert Franken (1994) sobre los aequipondia altoimperiales, tardoantiguos y altobizantinos, destaca como pieza de mayor peso un contrapeso de Budapest de 14,490 kg 
(Franken 1994, 195 CE4), al que luego nos referiremos (ver Fig. 12). Conocemos también en el Musee de Picardie de Amiens un contrapeso, aparecido con posterioridad a la obra de Franken, con imagen juvenil de Baco y un peso de 14,800 kg. Este contrapeso galo, fabricado en bronce con relleno de plomo, apareció en un depósito de bronces de Dury (Somme) y fue publicado por P. Querel y M. Feuguere (2000). Por su gran peso de 48 libras se ha sugerido que estuviera destinado al pesaje de lingotes (Bayard et alii 2006: 120-121, cat. 137).

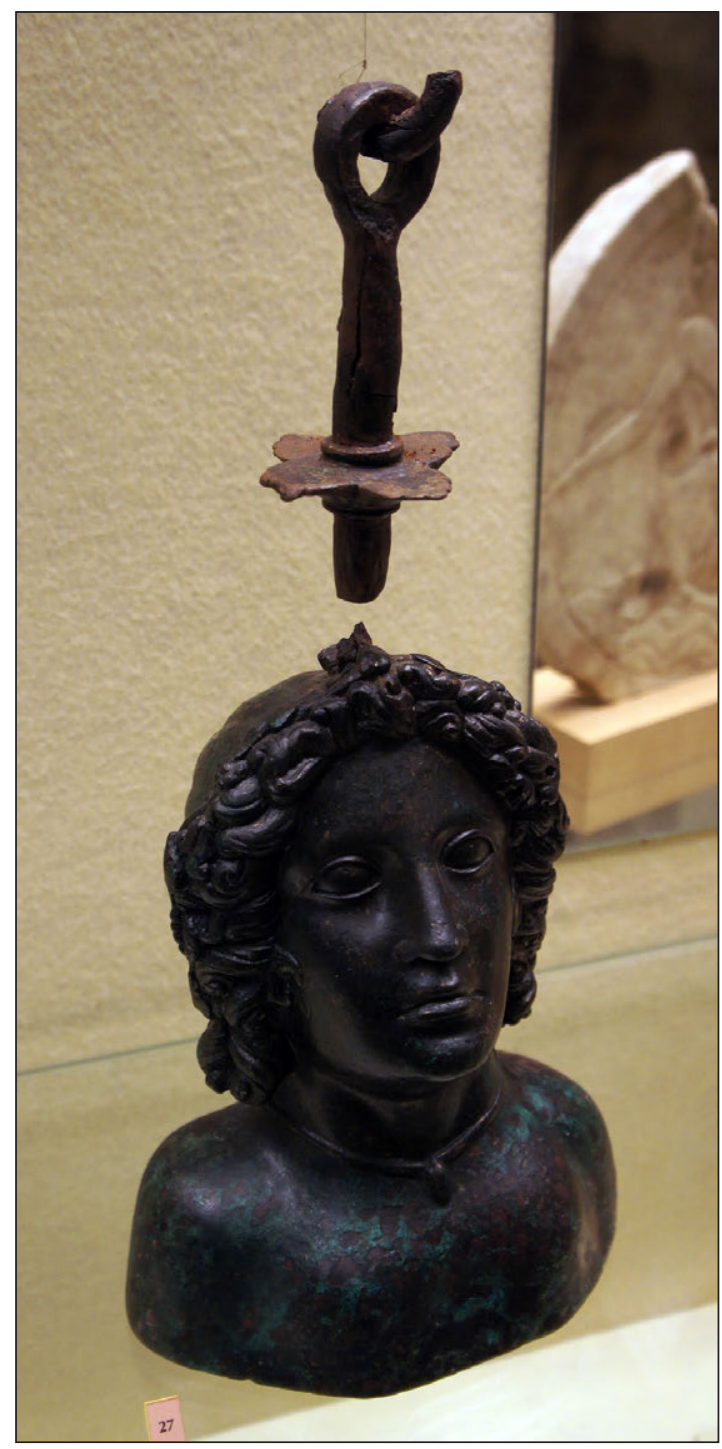

Figura 5. Contrapeso aparecido en un depósito de bronces de Dury (Somme) conservado en el Musee de Picardie de Amiens, con un peso de $14,800 \mathrm{~kg}$ (Bayard et alii 2006, 120-121, cat. 137).
Pero de las casi 50 libras que alcanzan ambos contrapesos, como decimos los más grandes de todos los hasta ahora publicados, encontramos ahora en Tarragona una pieza que dobla en mucho sus magnitudes alcanzado prácticamente las 120 libras. Y ello resulta bien extraño ya que manejar un contrapeso de $38 \mathrm{~kg}$ sobre el brazo o scapus de una romana debía representar una tarea fráncamente incómoda. Podemos asegurarlo después de haber movido y examinado la pieza personalmente. Además, un contrapeso de este tamaño y peso debería precisar como scapus de guía una gruesa barra de bronce o hierro sin duda de enormes proporciones. Una balanza así tan solo pudo funcionar colgada de una viga o de un gran caballete a modo de las grandes machinae mencionadas por Plinio. Acercarnos a las características de esta balanza gigantesca debe ser pues el primero de los temas a tratar.

\section{STATERAE. LAS BALANZAS DE BRAZO O RO- MANAS}

Los romanos, como todas las sociedades desde la Antigüedad a la época moderna, utilizaron conjuntamente dos sistemas de balanzas para pesar todo tipo de productos y objetos: las balanzas de platos y las balanzas de brazo. La balanza de platos (libra, talentum, trutina) fue la balanza clásica de egipcios y griegos. Consistía en un largo brazo horizontal ( $s c a-$ pus), aguantado por un punto central, fiel o fulcro (iugum, fulcrum), con dos platos (lances) situados en ambos extremos colgados a la misma altura por medio de anillas (asa) y cadenas. En uno de los platos se colocaba el producto a pesar y, en el otro, se igualaba su peso mediante unos ponderales fabricados con valores de medida preestablecidos (DA, s.v. libra -E . Micron-; Di Pasquale 2004: 331, Corti et alii 2010). La segunda variedad de balanza corresponde a la statera o balanza de brazo que tiene su origen en el principio físico conocido como ley de la palanca, habitual en el mundo antiguo desde época helenística y definido entre otros por Arquímedes de Siracusa. Es la balanza que conocemos hoy con el nombre genérico de "romana", elemento omnipresente en todos los mercados y en el mundo agrario hasta la aparición de la balanza electrónica en los años 1970.

La statera consiste en un brazo horizontal (scapus) con un fiel o fulcro (iugum) en posición desplazada que divide el brazo en dos partes muy desiguales. En la primera, a muy poca distancia del fiel, se colocaba el producto a pesar sobre un plato sostenido por cadenas y un gancho de suspensión. A continuación, sobre el brazo más largo, de sección ovoidal o romboidal, 
y dotado de marcas de control, se hacía deslizar un contrapeso (aquipondium) hasta conseguir la nivelación horizontal de la balanza con la masa anterior. La definición de Vitrubio (X, 3, 4) lo explica de forma sintética y clara:

Id autem ex trutinis, quae staterae dicuntur, licet considerare. cum enim ansa propius caput unde lancula pendet, ibi ut centrum est conlocata et aequipondium in alteram partem scapi, per puncta vagando quo longius aut etiam ad extremum perducitur, paulo et inpari pondere amplissimam pensionem parem perficit per scapi librationem examinatio. ita longius ab centro recedens inbecillior aequipondii brevitas maiorem vim ponderis momento deducens sine vehementia molliter ab imo sursum versum egredi cogit.

"Todo esto se puede comprobar en las balanzas denominadas estáteras. Cuando el asa, que es el centro, está colocada cerca del brazo que sostiene el peso y el cursor se desplaza hacia la otra parte del brazo, al moverlo por los puntos marcados, cuanto más se desplace hacia el extremo equilibrará un peso realmente gravoso con una pesa bastante menor debido a la nivelación que se alcanza del brazo y al desplazamiento del cursor respecto del centro. El escaso peso del cursor adquiere en un instante una mayor fuerza y propicia que suavemente y sin brusquedad se eleve un peso mayor hacia lo alto".

Por su comodidad, exactitud y fácil manejo, las staterae fueron las balanzas más utilizadas en el comercio romano al detalle. El Edictum de pretiis del siglo IV acredita que la carne se compraba a peso, tan solo los animales más pequeños se vendían por cabezas. Y efectivamente los relieves funerarios ostienses muestran conocidas escenas de compraventa en carnicerías que cuentan con staterae para pesar las piezas de carne. Pompeya ha proporcionado un número considerable de romanas y lo mismo ocurre a lo largo y ancho del mundo romano (DA, s.v. libra (E. Micron); Di Pasquale 2004: 294-295). El origen de la statera no es conocido con precisión, aunque S. Isidoro proponía en sus Etymologiae situarlo en la Campania: Campana a regione Italiae nomen accipit ubi primum usus repertus est. Haec duas lances non habet: sed virga est signata libris et unciis, et vago pondere mensurata. (Di Pasquale 2004: 310). Estamos hablando fundamentalmente de balanzas dedicadas al comercio minorista, equipadas con brazos de entre 30 y $50 \mathrm{~cm}$ de longitud y contrapesos de $300 \mathrm{gr}$ a $3 \mathrm{~kg}$.

El aequipondium del puerto de Tarraco, con sus $38 \mathrm{~kg}$ de peso, debería desplazarse por medio de un gancho de hierro del que todavía quedan restos soldados por la corrosión a la anilla superior. El scapus o barra de esta balanza debió ser un grueso brazo

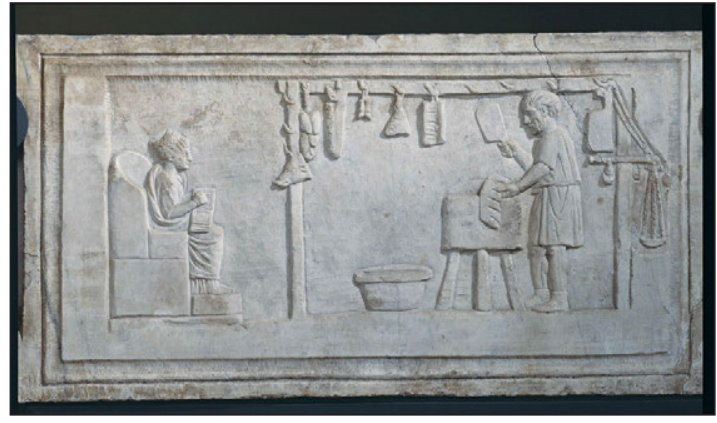

Figura 6. Relieve funerario mostrando una escena de carnicería con presencia en el lado derecho de una romana para el pesaje de la carne. Placa funeraria procedente de Roma conservada en Dresde (Franken 1994, D 4).

también de hierro o bronce macizo que pudo llegar a tener perfectamente dos metros de longitud o quizás más. Una statera de tal tamaño evidentemente debía estar suspendida de un sólido elemento de soporte, un sistema de envigado o un gran caballete construido $a d$ hoc, formando lo que Plinio denomina una machina.

La epigrafía de la Urbs recoge tres ejemplos mencionando a los mensores machinarii frumenti publici (CIL VI, 85; 9626; 3383), aunque éstos, en las representaciones figuradas, utilizaban preferentemente las grandes librae o básculas de dos platos o plataformas representadas por ejemplo en el sepulcro del pistor Eurysaces en Roma.

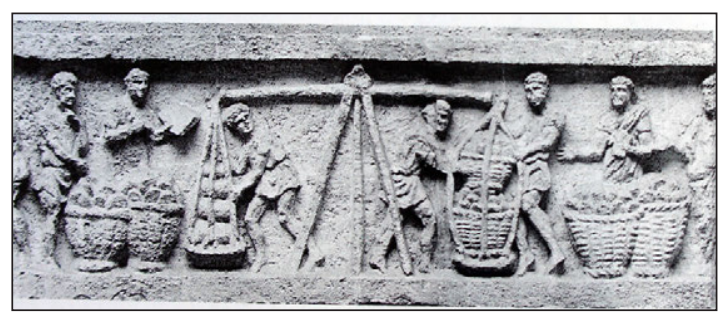

Figura 7. Utilización de una machina para el pesaje de los panes en el relieve superior del sepulcro de Eurysaces en Roma. En este caso se trata de una libra tradicional con dos platos. Los ponderales debían ser añadidos sucesivamente en uno de ellos hasta llegar a equilibrar el producto a pesar.

Conocemos sin embargo dos bellísimos y precisos relieves figurados que muestran también en acción dos gigantescas staterae de brazo montadas en machinae. El primero, procedente de Neumagen y datable en los siglos II o III d. C., está conservado en el Rheinisches Landesmuseum de Trier (Inv. 10032; cf. Franken 1994, 218, fig. 127, D8). Se trata de un relieve funerario de dimensiones cuadradas (h: $50 \mathrm{~cm}$ ) que muestra a un personaje, protegido por un largo delantal, moviendo el contrapeso de una gigantesca statera suspendida 
del techo o bien de un gran caballete de soporte. La balanza incluye un gran plato circular de pesada colgado de cadenas ocupado por un enorme fardo de contenido indeterminado, con dimensiones que obligaron incluso a deformar su imagen en el relieve.

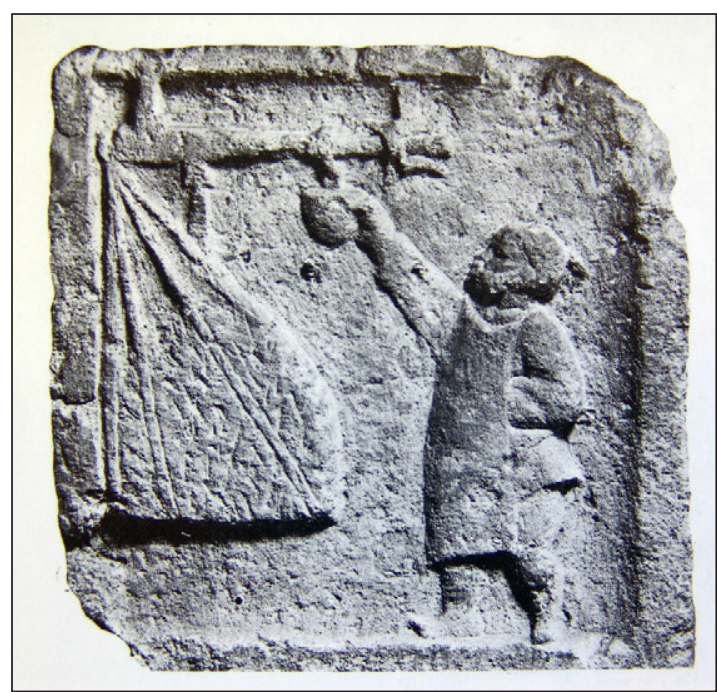

Figura 8. Machina. Funcionamiento de una gran statera montada sobre un caballete o viga. Relieve funerario de Neumagen conservado en el Rheinisches Landesmuseum de Trier. Altura: $50 \mathrm{~cm}$ (Franken 1994, D 8)

La escena muestra algunos detalles técnicos de interés. En primer lugar se aprecian claramente en la statera los dos fulcros colocados a diferentes distancias en los dos cantos opuestos del brazo. La báscula estaba pues diseñada para medir dos tipos de magnitudes diferenciadas, de mayor y menor pesada, sencillamente invirtiéndola. Una práctica técnica que se ha mantenido inalterable a lo largo de la historia. En segundo lugar el extremo del brazo por donde circula el contrapeso se encuentra encajado en el interior de un cuadrado metálico independiente a modo de sostén y tope. La finalidad práctica de este elemento, muy frecuente en estas grandes machinae, era impedir la sacudida del brazo al colgarse en el otro extremo el elemento a pesar antes de poder equilibrar la balanza con el contrapeso.

El segundo ejemplo, no recogido por Franken, es un magnífico relieve funerario conservado en la sala II del Museo Campano de Capua (num. reg. 315/645; h. 0,88 m; long. 0,98 m; grosor 0,37 m). Se trata de un bloque de mármol blanco aparecido en el siglo XVIII en las cercanías de la iglesia de la Magdalena de Capua, perteneciente también sin duda a la decoración exterior de un monumento funerario. El relieve muestra una escena de control de pesos por medio de una gran statera ante la cual figura un personaje o magistrado sentado en una silla. A su lado, un mensor sosteniendo en su mano izquierda un políptico o libreta de tablillas para las anotaciones, verifica con su mano derecha el equilibrio de una gigantesca romana, colgada una vez más de un techo o caballete cuyas dimensiones exceden a la escena. El bloque solo conserva el extremo de pesada de la gran balanza, con su brazo insertado de nuevo en un cuadro metálico cuadrangular pero esta vez junto al fulcro colgado de lo alto. Del brazo corto pende un gran plato suspendido por cadenas y sobre el mismo se han colocado apilados para su pesaje cuatro elementos que podrían ser quizás lingotes o panes de cobre.

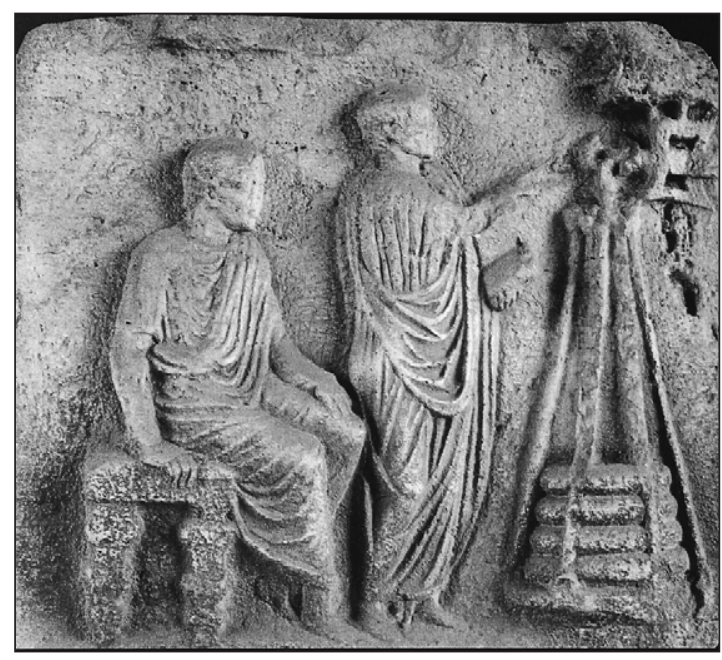

Figura 9. Machina. Relieve funerario de Capua con escena de control de pesadas por medio de una statera de gran tamaño pero de la que solo se ha conservado el extremo de carga y el fulcro. Procedente de Capua. Museo Campano. Altura: $88 \mathrm{~cm}$.

\section{UN POCO DE FÍSICA}

El principio de la ley de la palanca es muy simple: respecto al fulcro o eje de suspensión la nivelación de pesos en una statera o romana encontrará el equilibrio en el momento en que la fuerza total hacia la izquierda sea igual a la fuerza total hacia la derecha. La fórmula, por tanto, será la siguiente: $\mathrm{P}$ (peso) X $\mathrm{DP}($ Distancia del peso al fulcro $)=\mathrm{C}($ contrapeso $) \mathrm{x}$ DC (distancia del contrapeso al fulcro). Es decir que si colgamos en el extremo de un brazo un peso de $100 \mathrm{~kg}(\mathrm{P})$ a $2 \mathrm{~cm}$ de distancia del fulcro (DP), este brazo encontrará su equilibrio colgando por ejemplo un peso de $5 \mathrm{~kg}(\mathrm{C})$ a $40 \mathrm{~cm}$ de la distancia opuesta al fulcro (DC), siendo $100(\mathrm{~kg}) \times 2(\mathrm{~cm})=5(\mathrm{~kg})$ x $40(\mathrm{~cm})$. Pero el mismo equilibrio se obtendría también colocando un peso menor, de tan solo $2 \mathrm{~kg}$ 
(C), a una distancia mayor, en este caso de un metro (DC), siendo $100(\mathrm{~kg}) \times 2(\mathrm{~cm})=2(\mathrm{~kg}) \times 100(\mathrm{~cm})$. $\mathrm{Y}$ así sucesivamente.

La aplicación práctica de esta ecuación $\mathrm{P}$ x DP $=\mathrm{C}$ $\mathrm{x}$ DC para fabricar una romana consiste técnicamente en mantener fijos los parámetros DP (distancia del peso al fulcro) y C (magnitud del contrapeso). De esa forma, desplazando el contrapeso sobre el brazo en una serie de pruebas previas, resultará posible establecer las marcas de una regla graduada a lo largo del brazo o scapus con valores consecutivos a partir de 0 en el fulcro de origen (DC1, DC2, DC3...). Asî podremos despejar para cada una de ellas el valor correspondiente a $\mathrm{P}$ en nuestra ecuación. De esta forma, como nos decía Vitrubio, con una statera podremos saber el peso de un determinado producto colgándolo en el extremo menor del fulcro y a continuación desplazando el contrapeso sobre la regla graduada hasta que la balanza alcance el equilibrio.

Y existe además una segunda posibilidad complementaria. Como el brazo de medida debe ser colocado de canto para facilitar el desplazamiento del contrapeso por medio de un gancho de anclaje resulta posible colocar dos fulcros uno por cada canto de la barra y para cada uno de ellos hacer variable la distancia DP (del peso al fulcro). Así variará la relación de fuerzas y con una misma balanza podremos obtener pesadas mayores o menores y a su vez de precisión menor o mayor.

\section{¿PARA QUÉ PESADAS PUDO ESTAR CONFIGU- RADO ESTE AEQUIPONDIUM?}

Evidentemente, la respuesta precisa a esta pregunta dependerá de las diferentes magnitudes fijas de la balanza en la ecuación de la palanca. Para imaginar que aspecto y características podría tener una statera que utilizara un contrapeso de $38 \mathrm{~kg}$ hemos utilizado como paralelo técnico una gran romana fabricada en Almería en 1905 conservada en la colección del Museu de la Vida Rural de l'Espluga de Francolí (Tarragona). Se trata de un magnífico ejemplar firmado por S. Morales, fabricado en hierro colado con una longitud total de asta de $2,30 \mathrm{~m}$ rematada en una bola de bronce, barra de sección romboidal y $4,5 \mathrm{~cm}$ de grosor. Posee dos fulcra o ejes invertidos, uno situado a $18 \mathrm{~cm}$ del punto de pesada para magnitudes menores

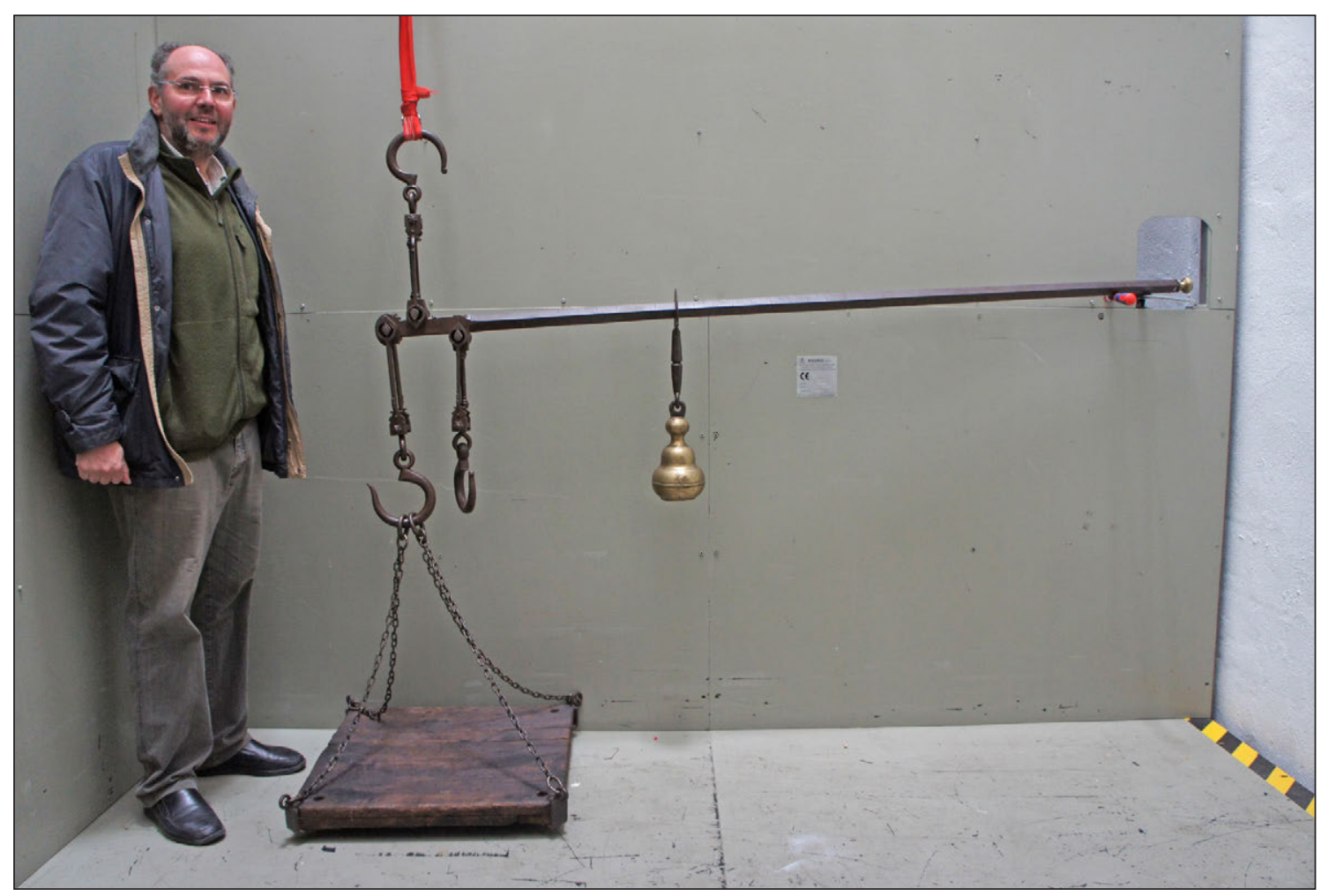

Figura 10. Gran romana fabricada en Almería en 1905 conservada en la colección del Museu de la Vida Rural de l’Espluga de Francolí que dirige Ramon Rosich, también en la imagen. Con un asta de 2,30 m, esta magnífica romana representa un paralelo muy próximo para imaginar el aspecto y las dimensiones que pudo alcanzar la statera a la que pertenecería nuestro aequipondium. 
de entre 80 y $230 \mathrm{~kg}$ según la regla graduada y otro a tan solo $7 \mathrm{~cm}$ para magnitudes mayores de entre 240 y $620 \mathrm{~kg}$ de pesada máxima, también marcadas en el asta en posición invertida. El contrapeso de esta balanza es de $21,7 \mathrm{~kg}$.

$\mathrm{Si}$ situamos nuestro contrapeso en una statera de las mismas proporciones, que por tamaño se aproximaría fielmente a los ejemplos citados en los relieves de Capua y Neumagen y sustituimos el contrapeso por nuestro aequipondium de $38 \mathrm{~kg}$ obtendríamos la siguiente posibilidad de pesada máxima: $\mathrm{P}$ x $7 \mathrm{~cm}$ $=38 \mathrm{~kg} \mathrm{x} 200 \mathrm{~cm}$ siendo por tanto $\mathrm{P}=1085 \mathrm{~kg}$. Es decir más de una tonelada de pesada máxima.

Si la distancia DP hubiera sido algo menor, de por ejemplo $5 \mathrm{~cm}$ lo que también parece apropiado a partir de los relieves citados tendríamos: P x $5 \mathrm{~cm}$ $=38 \mathrm{~kg}$ x $200 \mathrm{~cm}$ siendo por tanto $P=1520 \mathrm{~kg}$. Una pesada máxima de tonelada y media.

Ciertamente la machina asociada a un contrapeso así tenía que estar destinada primordialmente a controlar magnitudes enormes. No puede ser casual que este aequipondium pese $38 \mathrm{~kg}$ (repetimos, sin el gancho de anclaje) tan próximo a las 120 libras romanas, a pesar de que eso signifique que se trata de un elemento grande y muy pesado, engorroso de manejar para deslizarlo sobre el asta o scapus y que dificultaría mediaciones de precisión. Se trataba ciertamente de una balanza destinada únicamente a efectuar grandes pesadas.

\section{TIPOLOGÍA Y LECTURA ICONOGRÁFICA}

Hasta el momento, nuestro contrapeso tarraconense era considerado en términos generales como la representación de una divinidad femenina (Franken 1994, 195 CE1) y más concretamente una posible imagen de Diana (Caballero 1990: núm. 345 -I. Rodà-). Creemos posible ahora concretar esta atribución con una nueva propuesta que nos parece mucho más adecuada para las características excepcionales de la pieza.

El busto femenino lleva una túnica griega o quitón sin mangas, anudada por medio de dos fíbulas circulares de disco a la altura de los hombros, dibujando los senos abultados y recorriendo la espalda mediante un juego de pliegues propio de un sutil tejido de lino fino y delicado, y no de la rústica lana propia del arcaico peplos. No dispone de mangas y los brazos, como es habitual en los contrapesos, están únicamente proyectados, rematados con dos brazaletes de disco que sirven de topes finales.

La cara se observa fina, orbicular y estilizada, girada hacia la derecha con expresión ausente. Las cejas se presentan marcadas y los ojos muy bien de- finidos, con el derecho más hundido que el izquierdo. Las córneas y pupilas de los ojos, ligeramente rehundidos, estuvieron sin duda resaltados con pequeñas placas de pasta vítrea, hueso o cuerno. La nariz es larga y rectilínea. La boca, pequeña y carnosa, está cerrada remarcando una expresión serena y severa, ausente, con los ángulos externos bien dibujados. Las orejas se esconden bajo el volumen de cabello. Como ya hemos descrito, la cabeza y el cuello se inclinan hacia la derecha al modo griego rompiendo así una excesiva frontalidad. Los cabellos, realizados con gran detalle, alcanzan un gran volumen en todo su perímetro. Están peinados a partir de una raya central bien visible en la parte trasera y quedan recogidos por una cinta que resalta dos trenzas, una primera de gran volumen situada frontalmente en lo alto del cráneo y una segunda trasera a modo de moño cubriendo la nuca. Los cabellos sobrantes se extienden con bucles sobre ambos hombros dotando a la imagen de una gran plasticidad. La forma de los ojos y el toque de trépano son ya propios de una cronología imperial avanzada.

Si el contrapeso hubiera estado cortado a la altura del cuello se podría dudar si esta gran masa de cabellos trenzados pudiera corresponder a la figura juvenil y amanerada del Apolo del Liceo según el famoso modelo helenístico creado por el genial Praxíteles (LIMC s.v. Apollo). Aquí sin embargo el carácter femenino queda definido sin lugar a dudas por la combinación de los senos abultados cubiertos por un suave quitón de lino, túnica femenina por excelencia. Podemos descartar que se trate de una Afrodita / Venus que en ocasiones también presenta una trenza semejante, ya que entonces la desnudez sería el requisito iconográfico indispensable. Por todo ello, la atribución de la imagen ha podido concretarse por eliminación sin entrar en más detalles como una Artemisa / Diana (Caballero 1990: núm. 345 -I. Rodà-). Una atribución que podríamos aceptar sin reservas si la pieza hubiera sido de tamaño mucho menor (Simon y Bauchhenss 1984). Por tratarse de una pieza destinada a una báscula excepcional creemos que su lectura iconográfica debe ser distinta.

Las imágenes de divinidades son muy habituales en los contrapesos. Existe una amplia variedad tipológica e iconográfica para los aequipondia bien estudiada junto a los pondera por distintos trabajos de Carla Corti (2001a; 2001b: espec. 198-208) y R. Tarpini (2001). Los contrapesos más pequeños podían adoptar formas geométricas cónicas, o bien representar ánforas, bellotas, cáscaras de caracoles, manos, etc. Al aumentar los tamaños y acercarse los pesos a la libra romana y sus múltiplos las formas se generalizan como pequeños bustos con todo tipo de 
representaciones figuradas: niños, atletas, guerreros, emperadores, actores cómicos, personajes heroicos, y sobre todo bustos de divinidades. Las romanas a las que pertenecían todas estas piezas eran siempre, recordémoslo, instrumentos de control de las actividades cotidianas de compra y venta con contrapesos de magnitudes próximas a la libra de peso, en torno a los 322 / 324 gr.

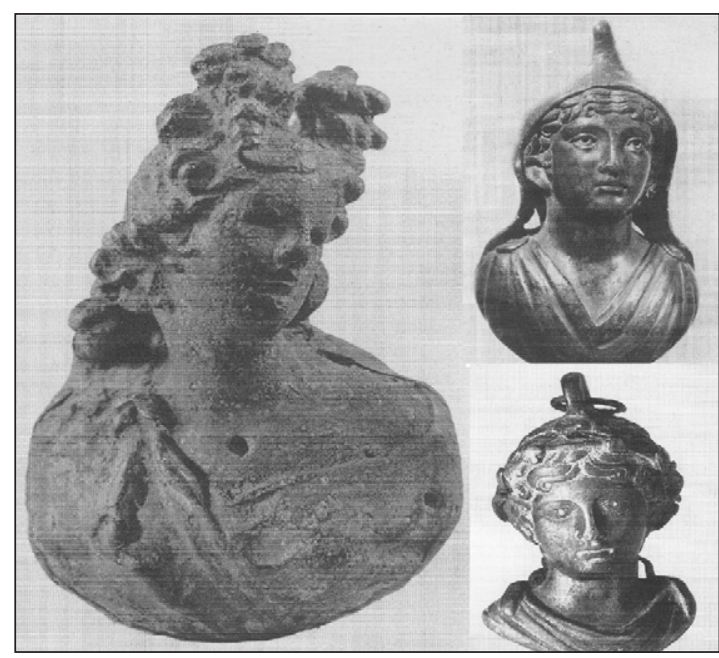

Figura 11. Ejemplos de contrapesos con imágenes de divinidades. A la izquierda Diana, a la derecha Attis y Mercurio. La doble trenza superior en una imagen femenina vestida con túnica corresponde tradicionalmente a representaciones de la diosa Diana.

Todos ellos han sido recogidos de forma monográfica por Norbert Franken (1994) en un amplio estudio iconográfico sobre un amplísimo catálogo de 429 ejemplares. Encontramos en ellos a Zeus / Júpiter dominante con barba y corona de laurel; Juno, Apolo y Diana, Mercurio, Dionisos o bien los sátiros y silenos de su cortejo, Attis, divinidades femeninas galeadas tipo Minerva o Roma, Hércules, Júpiter Amón, Isis y Serapis, Marte, Jano, Eros,... También emperadores toracatos o heroizados y todo tipo de imágenes diversas: atletas, aurigas, luchadores, púgiles, bustos de hombres y mujeres jóvenes o adultos, niños, esclavos nubios o incluso cráneos conviviales. Franken escogería precisamente la pieza tarraconense como portada de su obra, pero no pudo realizar la autopsia directa de la pieza (Franken 1994: 195 CE1). Por ello, tras recordar que el tipo de peinado con trenza podía corresponder a una Venus, Diana o quizás también Fortuna, prefirió simplemente considerar la imagen como una "deidad femenina".

Por su diversidad, la elección de imágenes figuradas para los aequipondia parecen basadas simple- mente en los recursos costumbristas propios de la vida cotidiana. Pero se trata, recordémoslo de nuevo, de ejemplares de tamaño infinitamente menor al tarraconense, de 300 gr de peso frente a los 38000 gr de nuestra pieza. Son por tanto órbitas de uso muy distintas. Y precisamente por ello existe otra posible lectura iconográfica que nos parece mucho más apropiada.

Nos explicamos. El Nationalmuseum de Budapest conserva un gran aequipondium encontrado en una fuente de Mitrovica, la antigua Sirmium, a inicios del siglo XIX, de nuevo decorado con un busto de deidad femenina (Franken 1994: 195, CE4). Es una pieza de dimensiones también considerables, con una altura de $27,5 \mathrm{~cm}$ y un peso de $14,490 \mathrm{~kg}$, el tercero mayor conocido tras nuestro ejemplar y el aequipondium con imagen de Mercurio del Museo de Amiens. El contrapeso de la romana de Sirmium representa - en somero arte provincial ya tardío - el busto de una mujer con el cabello recogido, como siempre de brazos truncados, cubierta por una túnica de cuello

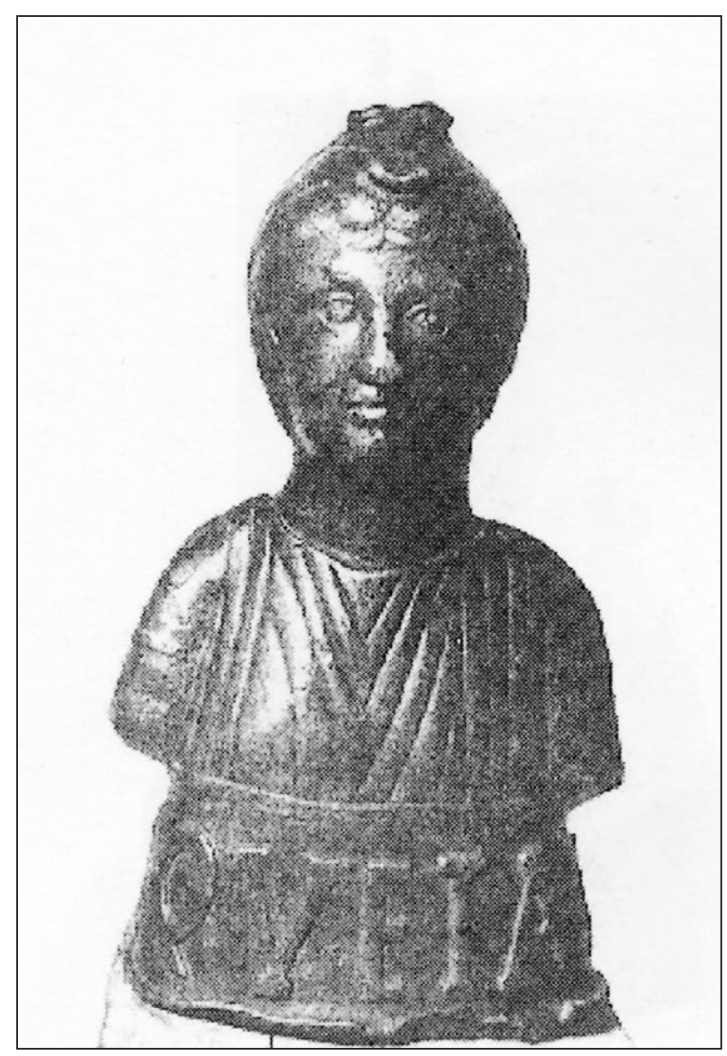

Figura 12. Aequipondium encontrado en Sirmium, conservado en el Nationalmuseum de Budapest. H: 27,5 cm. Peso: 14,490 $\mathrm{kg}$. Busto femenino con banda lisa inferior con inscripción de letras sobresalientes en altorrelieve EQUETAS (por Aequitas, la Equidad) (CIL III, 6015, 1; Franken 1994, 195, CE 4). 
cerrado, expresión serena y ausente. Pero lo realmente destacable en esta pieza es que la parte inferior del busto deja paso a una banda lisa que contiene la inscripción EQUETAS con letras sobresalientes en altorrelieve (CIL III, 6015, 1). Se trata por tanto de una imagen de Aequitas, la Equidad.

Hemos de hacer notar que no se trata de un ejemplo aislado. En Pompeya, CIL X, 8067 recoge grabada sobre otro aequipondium la inscripción X Equi(tis/tas). De esta forma, las dos únicas menciones epigráficas conocidas sobre aequipondia conteniendo nominales se concretan por igual en torno a esta virtud divinizada: la Equidad.

\section{AEQUITAS. LA EQUIDAD. ICONOGRAFÍA Y EPIGRAFÍA}

La Aequitas latina, como la griega Epieíkeia designa genéricamente un principio ético propio y necesario en las relaciones humanas que debe ser esperado por parte de quien ostente el poder jurídico o administrativo. Se trata del equilibrio como ideal natural en el trato entre los humanos reconocido como principio determinante al que debe acercarse también la Justicia, más estricta y rígida en su aplicación (v. por ejemplo Robles 2013). Así lo reconocía Elio Donato (adTer. $A d, \mathrm{I}, 26)$, el gramático del siglo IV d. C., en una bella frase transmitida luego a la filosofía cristiana: Inter ius et aequitatem hoc interest: Ius est quod omnia recta et inflexibilia exigit, aequitas est quae de iure multum remittit, "Entre la noción de derecho y la de equidad existe esta diferencia: el derecho exige rectitud e inflexibilidad; la equidad es la que modera en buena parte el derecho".

La iconografía de la Equidad, transmitida básicamente por la numismática, muestra una figuras femenina drapeada, con la cabeza descubierta, en posición sentada o alzada, llevando como atributos la balanza y la cornucopia, haciendo así corresponder el equilibrio con la abundancia (LIMC, s. v. Aequitas). Junto a la balanza, la Equidad puede portar también el globo en referencia a la propaganda imperial y la lanza o quizás mejor, como también se ha propuesto, la pertica o vara de diez pies necesaria en los repartos y delimitaciones agrarias. Su aparición en la iconografía monetal se inicia con aureos, denarios y ases de Otón y Vitelio en la crisis del 69 con inscripción Aequitas Augusti. Los reproducirán más adelante denarios y sextercios de Adriano y Antonino Pío con la misma iconografía y se popularizarán a fines del II d. C. con las emisiones de medallones de Septimio Severo (LIMC s. v. Aequitas, num. 1 y ss). Estas nuevas emisiones severianas muestran una relación de la Equidad con la propia Moneta en sus acuñaciones de oro, plata y bronce representando juntas a tres Aequitates con idénticos atributos de balanza y cornucopia y leyenda Aequitati publicae. Son emisiones y proclamas que se prolongarán hasta el emperador Decencio en el siglo IV d. C.

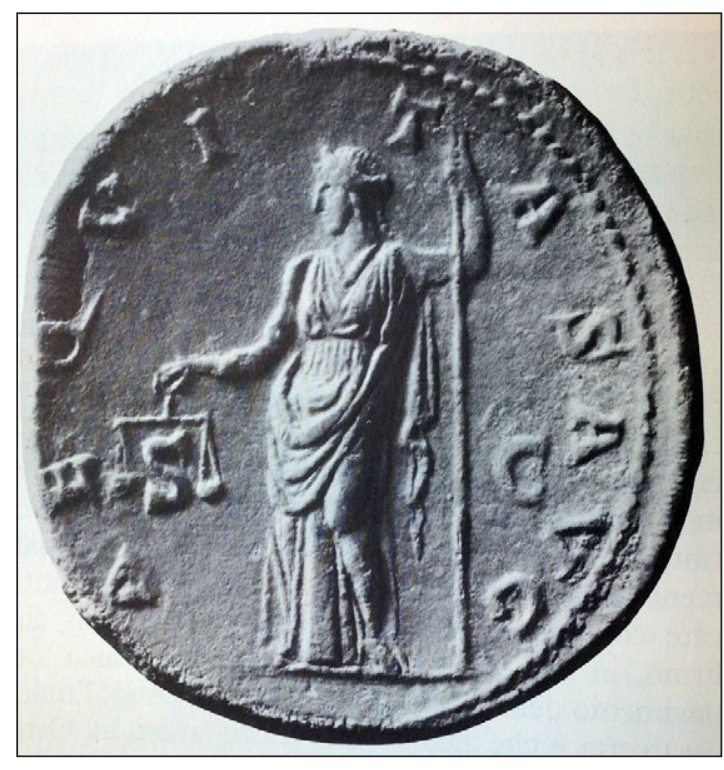

Figura 13. Representación monetal de Aequitas, la Equidad, en un sextercio de Adriano con leyenda Aequitas Aug[usti].

La Equidad está también igualmente presente en la epigrafía romana, siempre en torno a fora y macella, lugares públicos de mercado y comercio. Un trabajo de M. Christol (2012) ha estudiado algunos ejemplos significativos en las africanas Thugga y Uthina. En la primera ciudad, reaprovechada en un muro de la fortaleza bizantina, a poca distancia del macellum municipal, la inscripción CIL VIII, 26487 recoge el homenaje conjunto de $P$. Selicius al dios Mercurio y la Equidad Augusta: Mercurio [et] Aequitati Aug(ustae) [sacr(um)]. El dios Mercurio era con seguridad la divinidad protectora del mercado ya que una restauración encargada en época de Cómodo a expensas de $Q$. Pacuvius y Nahania Victoria afectó conjuntamente al macellum y al templo de Mercurio (CIL VIII, 26482). En Uthina, fue el edil C. Marius quien en época triunviral o poco posterior dedicó a su costa en el foro de la nueva colonia una estatua de la Equidad cumpliendo así un decreto decurional: C(aius) Marius C(aii) [f(ilius)] aedilis signum / Aequitatis sacrum / de sua pequnia ex d(ecreto) d(ecurionum) / faciundum coeravit (AE 2004, 1817). La Equidad poseyó por tanto una estatua, signum, pública, en una colonia africana casi 90 años antes 
que aparecieran en Roma sus primeras representaciones monetales. La Aequitas, para Christol (2001: 2143), es en estos ejemplos una segura referencia a la abstracción divinizada garante de la corrección de los pesos y medidas, responsabilidad de los ediles en la vida cotidiana del macellum.

La iniquitas latina podía referirse por igual a la desventaja de un lugar, por ejemplo para la batalla, iniquitas loci en César; pero también a la mala disposición de las cosas, iniquitas rerum, que utiliza Cicerón. En sentido general se refiere por igual a la injusticia o maldad. El castellano diferencia el sentido de la "inequidad" como una falta de equidad, diferente a la "iniquidad", directamente la maldad. La Aequitas latina debía de cualquier forma corregir los malos comportamientos del mercado, especialmente los originados por pesos y medidas falseados. Una lucha eterna y constante, para la cual nada mejor que los propios ediles proporcionaran a los lugares de compra y venta elementos técnicos necesarios y verificados, como sabemos ocurrió en la Pesaro romana: Ex iniquitatibus / mensurarum et ponder(um) / C(aius) Septimius Candidus et / P(ublius) Munatius Celer aed(iles) / et stateram aerea $(m)$ et pon/dera decret $(o)$ decur(ionum) / ponenda curaverunt (CIL XI, 6375). En Pisaurum, los dos ediles proporcionaron pues la romana hecha en bronce y los ponderales que garantizaran públicamente las transacciones impidiendo así los engaños. Otros epígrafes citados por M. Christol (2012: 2144 y nota 44) asocian ya directamente a la Aequitas con estas mejoras técnicas. En Filipos, Macedonia, el epígrafe AE 1935, 49 muestra a los ediles dedicando conjuntamente ponderales y una imagen de la Equidad: Aequitatis Augusti et mensuras...d(e) s(ua) p(ecunia) $f$ (aciendas) c(uraverunt) in id opus coiectum est ex mensuris iniquis aeris p(ondus) XXXXIIII. En la Narbonense, un epígrafe procedente de Murvielles-Montpellier, grabado sobre una mensa ponderaria, muestra la dedicatoria repetida Aequitati Aug(usti) por parte del edil C. Masclius Masculus. La Equidad, como divinidad aislada o asumida como virtud del poder imperial, Aequitas Augusti, aparece pues como la divinidad responsable de los pesos y medidas públicos, compañera por tanto en los macella de los otros dioses garantes del comercio como Mercurio o Hércules.

\section{CONCLUSIÓN ICONOGRÁFICA}

La interpretación de la imagen femenina que muestra el ponderal encontrado en el puerto tarraconense debe por tanto ser realizada desde dos ópticas complementarias: los elementos iconográficos propios de la imagen y las características técnicas de su soporte. Los primeros remarcarían la cinta o diadema, el sutil ropaje femenino y la gruesa trenza del peinado que cuadrarían perfectamente con una imagen de Diana o también Fortuna, siendo además cierto que ambas deidades aparecen representadas frecuentemente sobre los aequipondia del comercio minorista y el uso doméstico particular.

Pero ahora debemos valorar que la imagen, sin presentar símbolos iconográficos incontestables, puede también ser interpretada de una forma más precisa teniendo en cuenta la función de su soporte. En base a las evidencias epigráficas que acabamos de comentar, creemos mucho más lógico interpretar la imagen representada como la propia Aequitas al igual que ocurre en el aequipondium tardío de Sirmium, allí con el nombre claramente señalado. En ambos casos contemplamos imágenes femeninas adultas, de gesto tranquilo y ausente, vestidas con túnica sin ningún otro atributo específico que no sea su propio soporte. Desde luego, la trenza frontal del ejemplo tarraconense es uno de los atributos propios de la diosa Diana pero en ningún momento resulta excluyente para otras divinidades, sobre todo para una cronología imperial avanzada.

En una imagen que nada puede asir, pues carece de brazos, los símbolos iconográficos propios de Aequitas, como la balanza y la cornucopia carecen de lugar. La lectura iconográfica radicaría entonces simplemente en el carácter de elemento técnico de la propia imagen. La imagen de la diosa decoraba un contrapeso enorme que debía desplazarse a lo largo del brazo de una gigantesca romana colgada de un caballete o viga. Una gigantesca machina de pesaje que hemos de interpretar necesariamente como de carácter público y en la cual sin duda la presencia de Aequitas, era la que mejor aseguraba la imprescindible fiabilidad de la báscula.

\section{COMBATIENDO LA INEQUIDAD. UN PONDE- RARIUM O SACOMARIUM EN EL PUERTO DE TARRACO}

Toda balanza es un instrumento oficial de medida que para tener sentido precisa de una verificación oficial y así ocurría también en el mundo romano (Ahreus y Rottländer: 1993). Un trabajo publicado por A. D. Pérez Zurita (2011) se ha dedicado de forma específica a estudiar cuales fueron estas medidas de control y administración de los pesos y medidas en el occidente imperial romano. Resulta un útil complemento de trabajos anteriores de Carla Corti (2001a y 2001b) que ya hemos comentado, y 
del estudio epigráfico de C. Berrendonner (2009). Resulta igualmente útil la lectura de Mariagrazia Rizzi (2013) en la Revista internacional de Derecho Romano en un trabajo sobre los repetidos fraudes metrológicos documentados en las sociedades griega y romana.

Sabemos por Festo de la promulgación ya en el siglo III a. C. de una lex Silia o lex de ponderibus plebiscitaria que reglamentó las medidas de áridos y líquidos fijando penas para los transgresores (Cloud 1985 y 1996; Pérez Zurita 2011: 125-126) pero la situación nunca pudo ser regulada de una forma estable y global por lo que las reformas de control se fueron sucediendo durante toda la Antigüedad. Un avance importante debió producirse en el año 47 d. C. durante el mandato en Roma de los ediles $M$. Articuleius y Cn. Turranius que asumieron parece que con éxito un proceso oficial de tipificación de balanzas y ponderales. La norma que establecieron estos ediles romanos fue tenida como modelo a seguir como mínimo en Italia y quizás en todo el Imperio occidental ya que han sido diversos los hallazgos de balanzas y ponderales conteniendo fórmulas del tipo ponder(a) exact(a) [M(arco?)] Ar[ti] culei[o] Cn(aeo) Tur(ranio?) aedil(ibus) (CIL X, 8067.1 de Herculano); exacta ad Artic(uleianam) cura aedil(ium) (CIL X, 80672.2, de Herculano); iuss(u) aedili(um) exact(a) ad Artic(uleiana) (CIL XIV, 4124.2, de Praeneste) y así hasta 9 ejemplos diferentes (Pérez Zurita 2011: 125 tabla). La responsabilidad se trasladó más tarde al praefectus urbi, cuyos responsables tuvieron que ir restableciendo el sistema paulatinamente, y así lo hicieron los praefecti urbi Q. Innius Rusticus en el año 161 d. C., D. Simonius Proculus en el periodo 239/254 d. C. y Vettius Agorius en los años 367/368 d. C. (Rucinski: 2009; Pérez Zurita 2011: 127).

Las staterae incluían igualmente registros específicos de control de sus medidas y funcionamiento. Tales registros significaban que una balanza, ya acabada, con su plato, cadenas y contrapeso era verificada en Roma para su correcto funcionamiento y a continuación recibía un marcaje específico acreditativo. La marca de verificación era incluida por puntillado en la pieza mencionando únicamente su adecuación a las medidas oficiales a través de la expresión exacta in Capitolio, además del nombre y títulos del emperador como elemento de datación. Así lo demuestran algunos testimonios muy claros como la statera de Nápoles (CIL X, 8067.3), las dos encontradas en Valencia (AE 1989: 475; AE 2009: 655; Aranegui 1989) y una de Roma (ILS 8628). El Capitolio era pues el lugar donde estaban custodiadas estas muestras oficiales de pesas y medidas y sabemos por iguales referencias epigráficas que un segundo juego de piezas de referencia estaba también disponible en el templo de Cástor y Pólux en el foro romano. Quizás un tercero en el templo de Ops (Pérez Zurita 2011: 128, nota 18). En último lugar, la inscripción CIL VI, 282 fue dedicada en Roma por un pretoriano a un Hércules "de los ponderales": Herculi / ponderum / Q(uintus) Aemilius / Vibianus / b(ene)f(iciarius) tr(ibuni) coh(ortis) III [---] / O V.

Los foros de todas las ciudades romanas actuaron como lugares de mercado y por ello tuvieron que contar entre sus instalaciones con un lugar para situar los elementos de control de pesos, medidas y volúmenes bajo supervisión de los ediles. Las fuentes epigráficas lo denominan ponderarium u officina ponderaria. Contenía habitualmente una mensa con distintas cavidades destinadas al control de volúmenes en base al modius, reglas de medida de longitudes y balanzas (ya fueran librae de dos platos o staterae de brazo y contrapeso con sus ponderales respectivos). También es posible que este lugar público de control estuviera situado, con mayor propiedad, en un macellum o mercado de abastos vecino a la plaza forense (De Ruyt 1983; Chanskowski y Karonis 2010).

Nada sabemos en Tarraco sobre la ubicación de estos elementos concretos. Ni a nivel estructural ni por hallazgos epigráficos o de cultura material. Aunque en distintos trabajos hemos podido sugerir cual era el aspecto general de las plazas yuxtapuestas que fueron conformando el foro de la colonia, allí el único edificio bien conservado es la gran basílica jurídica construida en época de Augusto y Tiberio (Mar y Ruiz de Arbulo 2011; Mar et alii: 2012). Un edificio público destinado primordialmente a la actividad judicial urbana de los duoviros y la del propio gobernador provincial durante toda la época julio-claudia en relación al conventus y la provincia.

Siendo Tarraco una ciudad portuaria, y además capital provincial, sin duda tuvo que existir un segundo punto de control oficial de pesos y medidas situado en el propio puerto. Tanto para las propias transacciones privadas como para el control fiscal de la actividad portuaria. El barrio portuario tarraconense rodeaba la vaguada portuaria y el vecino paleocauce del río Tulcis, conformando un espacio muy amplio que constituía en sí mismo una entidad independiente extramuros separada de la propia ciudad quizás incluso jurídicamente. Han sido múltiples las excavaciones desarrolladas en los últimos tiempos en este barrio portuario (Adserias et alii 1993; Remolà y Vilaseca 1997-1998; Adserias et alii 2000; Pociña y Remolà 2001 y 2003; Bea 2006,) y por ello comenzamos a tener ya una idea aproximada de sus características. 


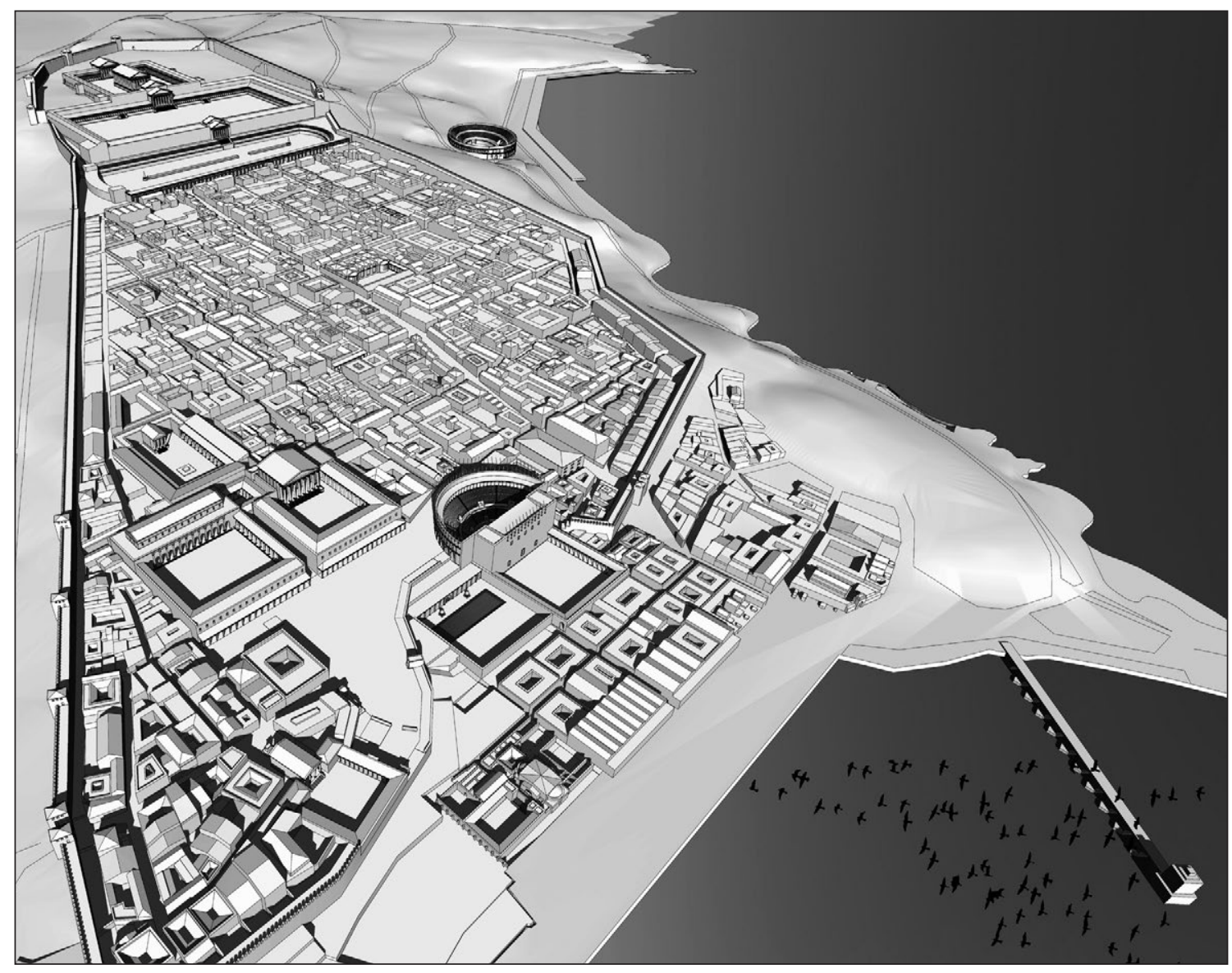

Figura 14. Reconstrucción de la ciudad de Tarraco en el siglo II d.C. según Ricardo Mar y José Alejandro Beltrán-Caballero, con los edificios portuarios situados en primer término. Uno de ellos albergaría el sacomarium o gran balanza pública del puerto cerca del cual apareció nuestro aequipondium.

Destacaría en primer lugar el gran muelle de pilares (opus pilarum), barrenado en el siglo XIX, que al igual que en Puteoli protegería el anclaje de las naves facilitando al mismo tiempo la evacuación de los lodos arrastrados por el río y evitando el arenamiento de la rada (siltation). Conocemos por la arqueología algunos de los horrea portuarios e incluso sabemos que en la Antigüedad tardía se desarrolló un barrio residencial portuario con un nivel adquisitivo importante (Pociña y Remolà 2001 y 2003; Macias y Remolà 2011; Mar y Guidi 2010). Al igual que ocurre en otros puertos cosmopolitas como Delos o Puteoli, la epigrafía documenta en el puerto tarraconense la existencia de templos, algunos dedicados a divinidades extranjeras que nos recuerda la presencia de las stationes de distintas comunidades de navegantes, establecidas en los puertos para facilitar los intercambios construyendo auténticos "consulados del mar" donde rendían culto a sus divinidades nacionales y ante cuyos altares podían cerrarse los tratos mediante juramento. Todos estos elementos debían hacer de la fachada marítima de Tarraco un auténtico escaparate internacional (Mar y Ruiz de Arbulo 2011).

Tarraco era, además de una colonia romana, también una capital provincial, lo que significa que su puerto tuvo que estar al servicio no tan sólo de la ciudad y de su agger sino también del gobierno provincial y de su fiscalidad. Tuvo por ello que contar con las instalaciones apropiadas para que los procuratores pudieran controlar un comercio interprovincial por vía marítima que estaba grabado por el impuesto específico de la quinta et vicesima venalium mancipiorum y verificar en general el cargamento de todas las naves llegadas a puerto. Una instalación fiscal de este tipo evidentemente tuvo que incluir instalaciones de medida, con modii y básculas para que los mensores pudieran realizar las comprobaciones oportunas. Una instalación así parece del todo apropiada en cualquier 

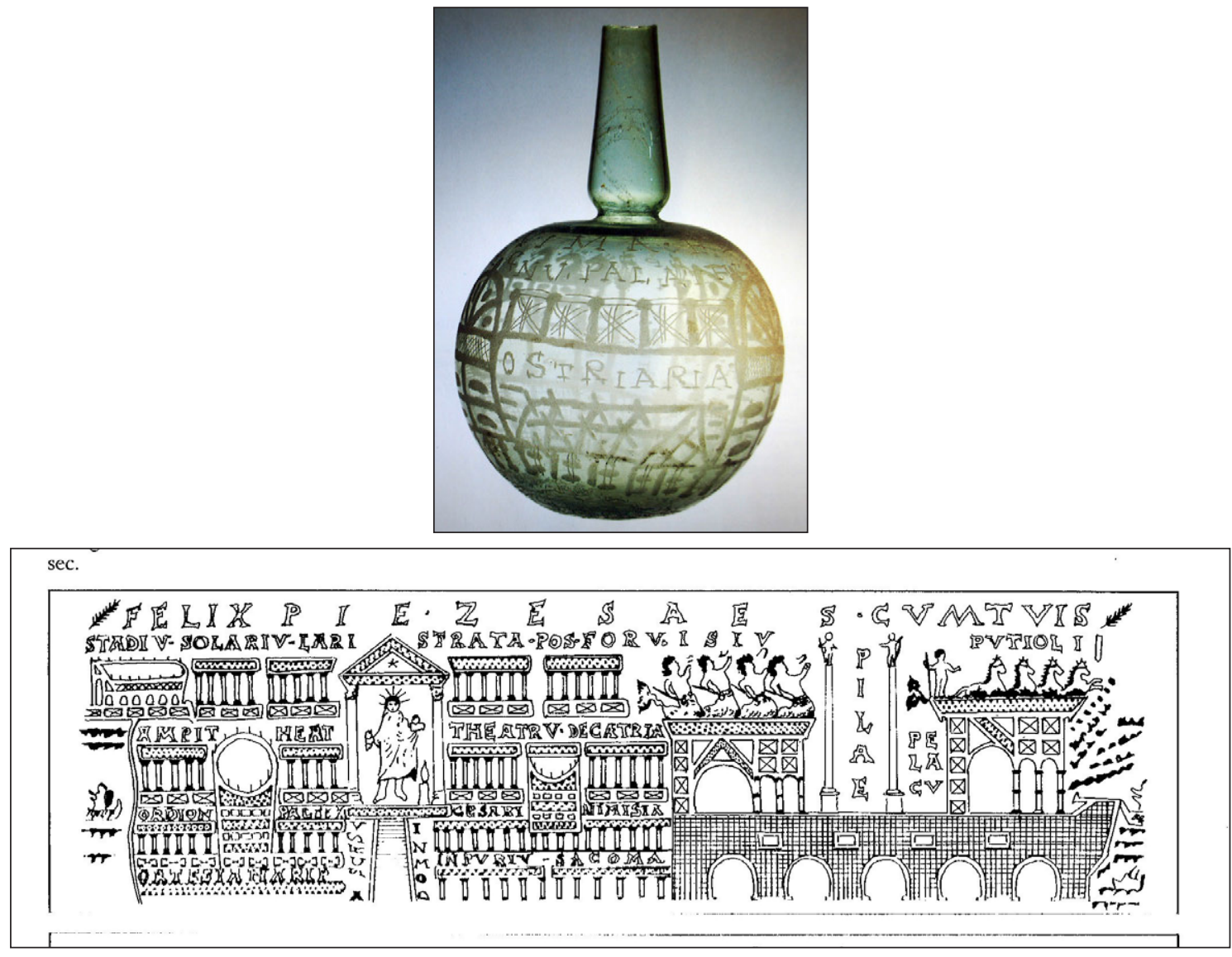

Figura 15. a. Botella de vidrio puteolana encontrada en Populonia. b. Desarrollo de la decoración de la botella puteolana conservada en el Museo Nacional de Praga mencionando junto al gran muelle de pilares, la presencia del іпригіи (por етроrium, el barrio portuario) y el sacoma[rium] o gran balanza pública (de Amalfitano et alii 1990, 81).

puerto con la finalidad de poder cerrar los tratos y comprobar de nuevo los fletes en el propio muelle a la llegada de las naves. En el puerto de Puteoli esta balanza pública, representada con su nombre sobre algunos de los vasos puteolanos, era denominada el Sacomarium. En ella trabajaba el liberto Stlaccius según menciona su epígrafe funerario: [---] Stlaccius A(uli) l(ibertus) Maric[---] / [--- m]ensor eidem sacom[arius] / sibi et sueis (CIL X, 1930).

La decoración del vaso puteolano de Praga, que reproducimos aquí, muestra a la derecha el gran muelle de pilares (pilae) junto al mar (pelagu), decorado con arcos culminados por esculturas de tema marino (cuadriga de hipocampos de Poseidón y cuadriga con tritones sonando conchas). A la izquierda, se desarrollan en terrazas los grandes monumentos, calles y barrios de la ciudad: Stadiu(m), Solariu(m), Strata post Foru(m), Amphiteat(rum), Theatru(m), (el barrio de) Decatria, etc. En el centro, el templo elevado de Isis (ascensu Domini). Junto al mar se dibujan los edificios de la ortesiana rip $(a)$, la ribera puteolana ocupada por grandes y lujosas villae, el Inpuriu (por Emporium, el barrio portuario extraurbano) y por último el Sacoma(rium) o gran báscula pública vecina al gran muelle de pilares.

En el puerto de Tarraco, un pequeño epígrafe grabado con letra cursiva antes de la cocción sobre el pivote de un ánfora asimilable a una Dressel 20 (MNAT, 45227) ha permitido sugerir a G. Fabre, M. Mayer e I. Rodà (IRC V, 138) la lectura Ad saco(marium) / T(arraconense, -arraconis). Para nuestros objetivos se trataría de un magnífico refrendo de la gran balanza pública portuaria pero hemos de mostrarnos prudentes. Las Dressel 20 fueron ánforas de aceite producidas de forma exclusiva en las riberas del Baetis y si el grafito se grabó ante cocturam el sacomarium citado debió corresponder a alguno de los grandes puertos fluviales béticos y no a Tarraco. Pero el pequeño tamaño del fragmento quizás permita una lectura tipológica diferente (no hemos podido todavía realizar la autopsia) 


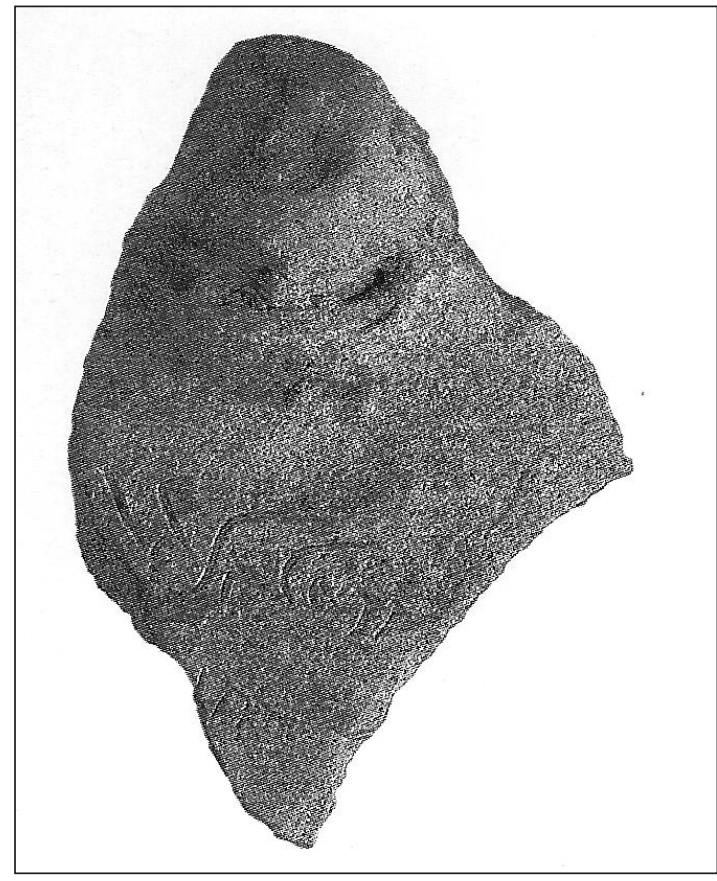

Figura 16. Fondo de un ánfora con grafito cursivo IRC V, 138: Ad saco(marium) / T(arraconensis, -arraconis), realizado ante cocturam.

y ciertamente los epigrafistas ya detectaron que la $T$ del grafito no guarda correspondencia con ninguno de los grandes puertos fluviales del Guadalquivir o las costas de la Bética.

La necesidad de controlar el peso de productos en magnitudes de toneladas nos indica en Tarraco la importancia del tráfico portuario interprovincial y la necesidad de su control efectivo con fines fiscales tanto en las salidas como en las llegadas de productos de todo tipo. No podemos precisar de momento si existió una relación con productos de la minería o la construcción monumental en mármol. Una posibilidad todavía poco estudiada para la época romana sería valorar la minería de la plata y el plomo de la vecina comarca del Priorat, atestiguada desde la época fenicia y protoibérica y mantenida a lo largo de las épocas medieval, moderna y contemporánea, por ejemplo en las minas de Bellmunt.

ANEXO. COMPOSICIÓN DEL METAL Y ANALITICA DEL PLOMO DE RELLENO DE BASE. Ignacio Montero, Instituto de Historia, CSIC. Madrid

La toma de muestras se realizó en las instalaciones del propio Museu Nacional Arqueològic de Tarragona.
Por un lado se tomaron partículas del metal mediante una abrasión controlada en una zona de la base. A partir de esta micromuestra, en el Microscopio electrónico de Barrido del Instituto de Historia se analizaron los pequeños restos extraídos para determinar la composición del metal. Se realizaron tres análisis diferentes en partículas distintas, seleccionándose aquellas que estuviesen más limpias de corrosión.

El valor medio obtenido es de 73,1\% Cu; 6,3\% $\mathrm{Zn} ; 8,3 \% \mathrm{Sn}$ y $12,3 \% \mathrm{~Pb}$. Por tanto se trata de una aleación cuaternaria o mixta.

Este tipo de aleaciones son frecuentes a partir del siglo III y IV d. C. y suelen interpretarse como producto de metales reciclados, en los que no hay un control preciso de cada uno de los elementos aleados. Llama la atención el que se emplee para una figura o estatua de metal colado ya que las aleaciones de esculturas romanas de época imperial suelen ser de bronce plomado normalmente con proporciones variables entre $65-80 \% \mathrm{Cu}, 15-30 \% \mathrm{~Pb}$ y $5-10 \%$ Sn según recoge y sintetiza Dungworth (1997) y hemos confirmado en algunas piezas analizadas por el Proyecto Arqueometalurgia de la Península Ibérica.

También se extrajo una muestra del plomo de relleno de la base, en este caso mediante un taladro con broca de 1,25 mm. La muestra se recogió en un tubo de polipropileno, químicamente inerte y libre de metales y fue enviada para el análisis de isótopos de plomo al Servicio de Geocronología y Geoquímica (SGIker) de la Universidad del País Vasco. La técnica utilizada ha sido espectrometría de masas de alta resolución y multicolección con fuente de plasma acoplado inductivamente (MC-ICP-MS Neptune). El resultado obtenido no permite interpretar un origen claro del plomo. El reciclado de plomo es una práctica frecuente y las ratios isotópicas obtenidas muestran que no hay coincidencia (Fig. 17) con los datos conocidos del área minera de La Unión en la Sierra de Cartagena y otras zonas del Sureste como Mazarrón o Sierra Almagrera y Cabo de Gata en Almería. Tampoco se pueden relacionar con otras áreas como Linares o Sierra Morena, por lo que lo más probable es que se trate de una mezcla del plomo en circulación, aunque con un origen mayoritario en el Sureste.

\section{BIBLIOGRAFIA}

Adserias, M., Bures, L., Miró, M. y Ramon, E. 1993: "L'assentament pre-romà de Tarragona", Revista d'Arqueologia de Ponent 3, 177-227.

Adserias, M., Pociña, C.A. y Remolà, J.A. 2000: "L'hàbitat suburbà portuari de Tàrraco. Excavacions al sector afectat pel Peri 2 (Jaume I - Ta- 


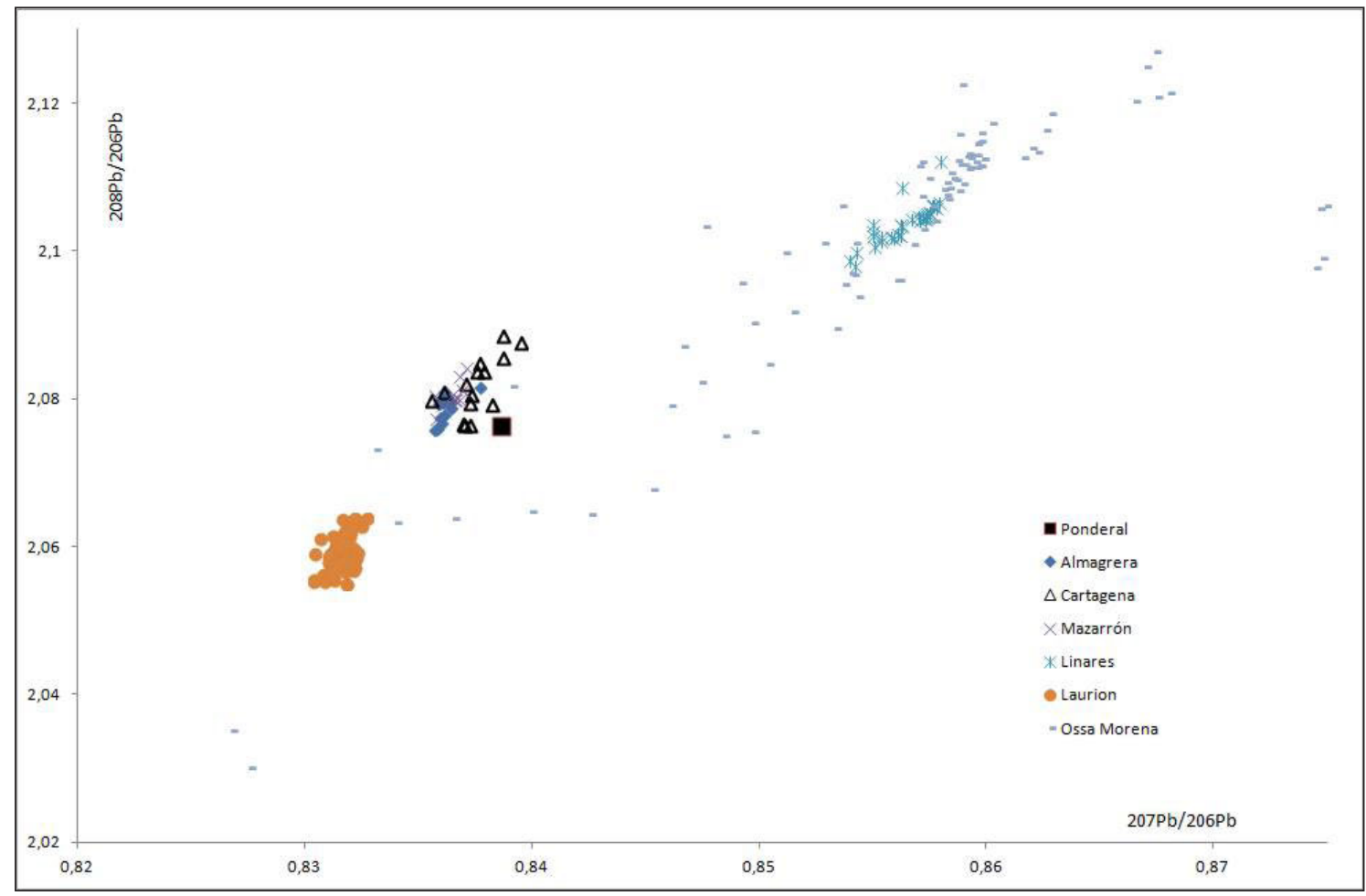

\begin{tabular}{|c|c|c|c|c|c|}
\hline Objeto & $\mathbf{2 0 8 P b / 2 0 6 P b}$ & $\mathbf{2 0 7 P b} / \mathbf{2 0 6} \mathbf{P b}$ & $\mathbf{2 0 6} \mathbf{P b} / \mathbf{2 0 4} \mathbf{P b}$ & $\mathbf{2 0 7} \mathbf{P b} / \mathbf{2 0 4} \mathbf{P b}$ & $\mathbf{2 0 8 P b} / \mathbf{2 0 4} \mathbf{P b}$ \\
\hline Ponderal (Figura) & 2,0763 & 0,83863 & 18,6913 & 15,6751 & 38,8086 \\
\hline
\end{tabular}

Figura 17. Tabla 1.- Valores isotópicos de la muestra del ponderal de Tarragona.

bacalera)", J. Ruiz de Arbulo (ed.), Tarraco 99. Arqueologia d'una capital de província romana, Tarragona, 137-154.

Ahreus, D. y Rottländer, R. C. A. (Hg.) 1993, Ordo et mensura II. II Internationaler interdisziplinärer Kongress für Historische Metrologie (Trier 1991), St. Katharinen.

Amalfitano, P., Camodeca, G. y Medri, M. 1990: I Campi Flegrei. Un itinerario archeologico, Napoli.

Aranegui, C. 1989: "Stadera romana hallada en Valencia", Archivo de Prehistoria Levantina 19, 263-264.

Bayard, D., Collart J. L., Mahéo, N. (Comis.) 2006: La marque de Rome. Samarobriva (Amiens) et les villes du nord de la Gaule, Catalogue de l'exposition au Musée de Picardie 2004, Amiens.

Bea, D. 2006: "El port romà de Tàrraco, aportacions historiogràfiques i noves interpretacions. La intervenció arqueològica als solars de l'UA 15 de Tarragona (Tarragonès)", Citerior. Arqueologia $i$ ciències de l'Antiguitat 4, 149-185.
Berrendoner, C. 2009: "La surveillance des poids et mesures par les autorités romaines: l'apport de la documentation epigraphique latine", Cahiers Glotz. 20, 351-370. http://dx.doi.org/10.3406/ ccgg.2009.1708

Berti, F. (ed.) 1990: Fortuna Maris. La nave romana di Comacchio, Bologna.

Caballero, L. (comis.) 1990, Los Bronces Romanos en España, Catálogo de la exposición en el Palacio de Velázquez, Madrid.

Chanskowski, V. y Karonis, P. (eds.) 2010: Tout vendre, tout acheter. Structures et equipements des marchés antiques (Atenas 2009), Athens.

Chaves Tristán, F. y Pliego Vázquez, R. 2007: "Instrumentos de medida de pesos en la Hispania Antigua", Sautuola 13, 237-250.

Christol, M. 2012: 'L'Equité, una composante de l'epigraphie du marché et de son decor: l'exemple africain", L'Africa romana, XIX, Roma, 2135-2152.

Cloud, J. D. 1985: “A lex de ponderibus (Festus, p. 288 L)”, Athenaeum 63, 405-418. 
Cloud, J. D. 1996: “Lex Silia”, Crawford, M.H. (ed.), Roman Statutes, vol. 2, London, 737-739.

Corti, C. 2001a: "Pesi e misure nei commerci, arti, mestieri e professioni”, C. Corti y M. Giordani (a cura di), Pondera. Pesi e mesure nell'Antichità, Campogalliano, 143-166.

Corti, C. 2001b: "Pesi e contrappesi", C. Corti y M. Giordani (eds.), Pondera. Pesi e mesure nell'Antichità, Campogalliano, 191-212.

Corti, C. 2001c: "Le merci e i mercati: sistemi e modalità di quantificazione nei commerci marittimi e fluviali di epoca romana", L'Archeologia dell'Adriatico dalla Preistoria al Medioevo (Ravenna 2001), Ravenna, 317-323.

Corti, C., Pallante, P. y Tarpini, R. 2001: "Bilance, stadere, pesi e contrapesi nel Modenese", C. Corti y M. Giordani (edsi), Pondera. Pesi e mesure nell'Antichità, Campogalliano, 271-313.

$D A=$ Daremberg, E., Saglio, E. (dirs.) 1877 y ss: Dictionnaire des Antiquités Grecques et Romaines. París.

De Ruyt, C. 1983: Macellum. Marché alimentaire des Romains, Amsterdam.

Di Pasquale, G. 2004: Tecnologia e meccanica: transmissione dei saperi tecnici dall'età ellenistica al mondo romano, Firenze.

Erice Lacabe, R. 2015: An "Aequipondium" from Sofuentes, Mid-Ebro valley, Spain, E. DeschlerErb, Ph. Della Casa (eds.): New Research on Ancient Bronzes. Acta of the XVIIIth International Congress on Ancient Bronzes, Zurich Studies in Archaeology 10, 147-150.

Dungworth, D. 1997: "Roman Copper Alloys: Analysis of Artefacts from Northern Britain". Journal of Archaeological Science 24: 901-910. http://dx.doi.org/10.1006/jasc.1996.0169

Franken, N. 1994: Aequipondia. Figürliche Laufgewichte römischer und frühbyzantinischer Schnellwaagen, Bonn.

IRC V = Fabre, G., Mayer, M., Rodà, I. 2002: Inscriptiones Romaines de Catalogne V. Supplement... et instrumentum..., ParisIMC $=$ Lexicon Iconographicum Mythologiae Classicae, Zürich/ München/ Düsseldorf.

Macias i Solé, J. M. y Remolà, J. A. 2011: "Portus Tarraconensis (Hispania Citerior)", Bolletino di Archeologia on line. Volume Speciale (Roma 2008. International Congress of Classical Archaeology. Meetings between cultures in the Ancient Mediterranean), Roma, 129-140.

Mar, R. y Guidi, J. J. 2010: "Formación y usos del espacio urbano tardoantiguo en Tarraco", I Congreso Internacional de Espacios Urbanos, siglos VI-VIII d. C., Madrid, 173-182.
Mar, R. y Ruiz de Arbulo, J. 2011: "Tarragona romana. República i Alt Imperi (anys $218 \mathrm{aC}-265 \mathrm{dC}$ )", M. Duch, M. (coord), Historia de Tarragona, 1, Lleida, 207-334.

Mar, R., Ruiz de Arbulo, J., Vivó, D. y Beltrán, J.A 2012: Tarraco. Arquitectura y urbanismo de una capital provincial romana, 1, Tarragona.

PAT 2007 = Macías, J.M., Fiz, I. (eds.), Planimetria Arqueològica de Tàrraco, Documenta, 5, Tarragona.

Pérez, W. 2007: Troballes arqueològics al litoral tarragoní. 12 anys d'arqueologia subaquàtica (1968-1980), Valls.

Pérez Zurita, A. 2011: "Control y administración de pesos y medidas en las ciudades del Imperio romano (Pars Occidentalis)", Gerión 29, 1, 123-148. http:// dx.doi.org/10.5209/rev_geri.2011.v29.n1.39048

Pociña, C. A. y Remolà, J. A. 2001: "Nuevas aportacions al conocimiento del Puerto de Tarraco (Hispania Tarraconensis)", Saguntum 33, 85-96.

Pociña, C. A. y Remolà, J. A. 2003: "Una font monumental a l'àrea portuària de Tàrraco. Notes preliminars", Empúries 55, 41-47.

Querel, P. y Feuguere, M. 2000: L'etablisement rural antique de Dury (Somme) et son dépot de bronzes (III s. av.J.-C. - IV s. ap. J.-C), Revue du Nord, num. special, 6, Lille.

Remolà, J. A. y Vilaseca, A. 1997-1998: "Intervencions arqueològiques al PERI-2, sector Tabacalera, de Tarragona", Tribuna d'Arqueologia, 77-96.

Rickman, G.E. 1971: Roman granaries and store buildings, Cambridge.

Rizzi, Mg. 2013: "Ex iniquitatibus mensurarum et ponderum. Appunti intorno alle frodi metrologiche nell'Antichità greca e romana", Revista Internacional de Derecho Romano 11, 288-331.

Robles, L. M. 2013: "Aequitas y sus relaciones con la Equity: diferencias, similitudes, influencias", Revista Internacional de Derecho Romano 10, 291-319.

Ruzinski, S. 2009: Praefectus urbi. Le gardien de l'ordre public à Rome sous le Haute-Empire romain, Poznan.

Sada, P. y Cazes, D. (coords.) 2006: Tarraco. Capitale de l'Hispania citerior, Catalogue de la exposition Musée Saint-Raymond de Toulouse, Graulhet.

Simon, E. y Bauchhenss, G. 1984: s.v. "Artemis/ Diana", Lexicon Iconographicum Mythologiae Classicae, Zürich/ München/ Düsseldorf, 793-855.

Tarpini, R. 2001: "Bilance e stadere", C. Corti y M. Giordani (eds.), Pondera. Pesi e mesure nell'Antichità, Campogalliano, 179-190.

Recibido: 18-03-2015

Aceptado: 14-07-2015 